\title{
El recurso especial en materia de contratación regulado en la Ley 34/2010, de 5 de agosto, actualmente incluida en la Ley 3/2011, de 14 de noviembre (TRLCSP)
}

\author{
José Manuel Martínez Fernández \\ Oficial Mayor Ayuntamiento de León \\ Josemanuel.martinez@aytoleon \\ Amaya Fernández García \\ Doctora en Derecho y Técnico de Gestión en el Ayuntamiento de León
} amaya.fernandez@aytoleon

\section{Resumen}

Este trabajo analiza el recurso especial en materia de contratación en la regulación que le dio la Ley 34/2010, de 5 de agosto, de modificación de la Ley 30/2007, de 30 de octubre, de Contratos del Sector Público, y que ha sido incorporado literalmente en el Texto Refundido de la Ley de Contratos del Sector Público, aprobado por el Real Decreto Legislativo 3/2011, de 14 de noviembre. Esta regulación es la transposición a nuestro ordenamiento jurídico de la Directiva 2007/66/CE, de 11 de diciembre, por la que se modifican las Directivas 89/665/CEE y 92/13/CEE del Consejo en lo que respecta a la mejora de la eficacia de los procedimientos de recurso en materia de adjudicación de contratos públicos. El estudio analiza las cuestiones objetivas, subjetivas y procedimentales de esta nueva regulación, prestando especial atención a la aplicación del recurso especial a las Entidades Locales. En estas Administraciones el recurso está en gran medida condicionado por la creación por parte de las Comunidades Autónomas de sus respectivos Tribunales Administrativos Autonómicos de Recursos Contractuales: en tanto las Comunidades Autónomas no creen estos Tribunales, la resolución del recurso especial en las Entidades Locales por el mismo órgano de contratación, lo convierte en un mero recurso administrativo equivalente al de reposición, pero con la "penalización" de que sus resoluciones usualmente no serán ejecutivas hasta que sean firmes.

Palabras clave

Regulación, recurso especial en materia de contratación, Tribunal de recursos.

\section{The Special Administrative Appeal in Public Sector Contracts given by Law 34/2010, of August 5th,amending Law 30/2007 of October 30 th, actually included in Law 3/2011, November 14th}

\footnotetext{
Abstract

This paper analyzes the special administrative appeal in contracts in the regulation of contracts given by Law 34/2010, of August 5, amending Law 30/2007 of October 30, Public Sector Contracts, which had been are incorporated literally in the Consolidated Act on Public Sector Contracts, approved by Royal Legislative Decree 3/2011 of 14 November. This regulation transposes into our legal system Directive 2007/66/EC of 11 December, amending Directives $89 / 665 / \mathrm{EEC}$ and $92 / 13 / \mathrm{EEC}$ with regard to improving the effectiveness of review procedures concerning the award of public contracts. The study analyzes the objective and subjective issues and procedural aspects of this new regulation, with particular attention to the implementation of special administrative appeal to Local Authorities. In these Administrations, in order to put in operation this administrative appeal, it is necessary the existence of specific Administrative Courts related to contractual issues, that is, a specific court of appeals created by the Regional Governments ("Comunidades Autónomas" in Spain): while the Regional Governments do not institute these courts, the decision of the special appeal in the Local Authorities by the same contracting authority, it becomes a mere administrative appeal, equivalent to the "replacement" appeal, but with the penalty that their decisions will usually not be enforceable until they are firm (not appeal).
}

Key words

Regulation, contracts special administrative appeal, court of appeals. 


\section{ANTECEDENTES Y REGULACIÓN NORMATIVA DEL RECURSO ESPECIAL}

Es importante considerar el origen de la norma, ya que su interpretación se ha de hacer a la vista de la normativa comunitaria que transpone, y de la doctrina del Tribunal de Justicia de las Comunidades Europeas sobre este recurso, como se pondrá de manifiesto a lo largo de este trabajo'.

El recurso especial en materia de contratación se articuló por primera vez en nuestro ordenamiento a través de la Ley 30/2007, de 30 de octubre, de Contratos del Sector Público con el propósito, como la propia exposición de motivos de la Ley señala, de trasponer la Directiva 89/665/CEE del Consejo, de 21 de diciembre de 1989, relativa a la coordinación de las disposiciones legales, reglamentarias y administrativas referentes a la aplicación de los procedimientos de recurso en materia de adjudicación de los contratos públicos de suministros y de obras, tal y como ha sido interpretada por el Tribunal de Justicia de la Unión Europea.

La regulación inicial de la LCSP fue profundamente corregida a través de la Ley 34/2010, de 5 de agosto, para incorporar la Directiva 2007/66/CE, de 11 de diciembre, que modificó sustancialmente las anteriores Directivas Comunitarias $89 / 665 / \mathrm{CEE}$, de 21 de diciembre y 92/13/CEE, de 25 de febrero, que regulaban los recursos en materia de contratación tanto con referencia a los contratos del Sector Público, como con respecto de los que celebren las entidades contratantes en los sectores del agua, la energía, los transportes y los servicios postales. La Ley 34/2010 añadió un Libro VI en la LCSP, titulado "Régimen especial de revisión de decisiones en materia de contratación y medios alternativos de resolución de conflictos”, comprensivo de los artículos 310 a 320 . Persigue esta reforma, en palabras también de su exposición de motivos:

"reforzar los efectos del recurso permitiendo que los candidatos y licitadores que intervengan en los procedimientos de adjudicación puedan interponer recurso contra las infracciones legales que se produzcan en la tramitación de los procedimientos de selección contando con la posibilidad razonable de conseguir una resolución eficaz. Para ello, la Directiva establece una serie de medidas accesorias para garantizar los efectos de la resolución que se dicte en el procedimiento de impugnación".

Este régimen reforzado de recursos en materia de contratación previos a los jurisdiccionales introducido por la Ley 34/2010, se ha incorporado al Real Decreto Legislativo 3/2011, de 14 de noviembre por el que se aprueba el Texto Refundido de la Ley de Contratos del Sector Público, en el capítulo IV del Libro I, artículos 40 a 50, con la misma denominación que en la norma de procedencia y básicamente con el mismo contenido, salvo las siguientes correcciones:

- Artículo 40, actos recurribles: incorpora en el punto 2 in fine la modificación que en el artículo 310.2 del TRLCSP introdujo la Ley 24/2011, de 1 de agosto, de contratos del sector público en los ámbitos de la defensa y de la seguridad: excluye del recurso especial los acuerdos sobre modificaciones no previstas en el pliego que sea preciso realizar una vez adjudicados los contratos.

-Artículo 41, órgano competente para la resolución del recurso: incorpora un punto 2 dedicado a la previsión de que las Cortes Generales creen su propio órgano para resolver el recurso especial en su ámbito de contratación.

- Artículo 49, efectos de la resolución: hace una corrección formal, cambiando el calificativo "financiero" de la LCSP por "interno" en el TRLCSP, al establecer que los actos dictados por los órganos competentes para la resolución del recurso especial no estarán sujetos a fiscalización por "los órganos de control interno de las Administraciones a que cada uno de ellos se encuentre adscrito".

\section{NATURALEZA JURÍDICA DEL RECURSO ESPECIAL}

El recurso especial en materia de contratación regulado en el artículo 40 del Texto Refundido de la Ley de Contratos del Sector Público, es un recurso ADMINISTRATIVO, no judicial, ad hoc en materia de contratación, para determinados contratos.

Es un recurso exclusivo y excluyente de otros recursos administrativos, cuando resulta procedente, es decir, no cabe la interposición de recursos administrativos ordinarios contra los actos enumerados en el artículo 40.5 del TRLCSP:

"No procederá la interposición de recursos administrativos ordinarios contra los actos enumerados en este artículo, salvo la excepción prevista en el siguiente con respecto a las Comunidades Autónomas."

1 La evolución normativa a nivel comunitario y español es analizada con detalle por Ballesteros Moffa, L.A., en el artículo “Comentario a la Ley 34/2010, de 5 de agosto, de modificación de las leyes de contratación pública en materia de recursos, y de la Ley de Jurisdicción ContenciosoAdministrativa", Justicia Administrativa, núm. 50, 2011, págs. 25 a 45. 
Esta regla general podrá se excepcionada por las Comunidades Autónomas, cuando éstas regulen la creación del órgano competente para resolver estos recursos en su ámbito territorial para los contratos de sus respectivas administraciones y de las EELL de su ámbito territorial (artículo 311.2.párrafo segundo):

"Las Comunidades Autónomas podrán prever la interposición de recurso administrativo previo al contemplado en el artículo 310".

Pese a lo anterior, no parece que nada impida a los órganos de contratación de las EELL y CCAA, en tanto éstas creen los órganos que han de resolver este recurso especial en su ámbito, que los pliegos reguladores de los contratos que por su cuantía no están sujetos a regulación armonizada, admitan la interposición de este recurso especial de manera potestativa, si bien en este caso no existe cobertura legal expresa para excluir con la interposición de este recurso, los recursos ordinarios regulados en la Ley 30/1992.

Por otro lado, con ocasión de la reforma de la Ley 34/2010, se modificó el artículo 44 de la Ley de la Jurisdicción Contencioso-Administrativa, añadiendo el siguiente párrafo:

"Cuando la Administración contratante, el contratista o terceros pretendan recurrir las decisiones adoptadas por los órganos administrativos a los que corresponde resolver los recursos especiales y las reclamaciones en materia de contratación a que se refiere la legislación de Contratos del Sector Público, interpondrán el recurso directamente y sin necesidad de previo requerimiento o recurso administrativo".

Asimismo, es un recurso de carácter POTESTATIVO (art. 40.6 del TRLCSP), frente a la obligatoriedad que preveía la anterior redacción del artículo 37.1 LCSP (en el que se enunciaban las decisiones que "deberán ser objeto del recurso especial"). En consecuencia, si así lo decide el recurrente, puede interponer directamente el recurso contencioso administrativo contra los actos enumerados en el artículo 40.2 del TRLCSP, sin presentar previamente el recurso especial en materia de contratación.

\section{LEGITIMACIÓN ACTIVA PARA LA INTERPOSICIÓN DEL RECURSO ESPECIAL EN MATERIA DE CONTRATACIÓN}

Como señala el Tribunal de Justicia de las Comunidades Europeas (STJCE de 14 de junio de 2003 C-249/01; STJCE de 12 de febrero de 2004, C-230/02), el recurso especial en materia de contratación es un recurso con un ámbito de aplicación material y de legitimación limitado, por lo que ha de analizarse el ámbito objetivo y subjetivo de actuación de este recurso.

En cuanto a los sujetos legitimados para interponer el recurso especial en materia de contratación, el artículo 42 del TRLCSP dispone lo siguiente:

“Podrá interponer el correspondiente recurso especial en materia de contratación toda persona física o jurídica cuyos derechos o intereses legítimos se hayan visto perjudicados o puedan resultar afectados por las decisiones objeto de recurso."

En parecidos términos se pronunciaba la anterior redacción del apartado 3 del artículo 37 de la LCSP:

"3. El recurso podrá interponerse por las personas físicas y jurídicas cuyos derechos o intereses legítimos se hayan visto perjudicados o puedan resultar afectados por las decisiones objeto de recurso y, en todo caso, por los licitadores."

La única diferencia existente entre la redacción actual del artículo 42 del TRLCSP y el pretérito artículo 37, se refleja en que se ha excluido la referencia expresa a los licitadores, quizás por considerar que su interés legítimo es evidente y que es una redundancia su mención, ya que nadie puede dudar de que los licitadores ostentan derechos o intereses legítimos que pueden verse afectados por las decisiones que se adopten en el procedimiento contractual. Sobre esta cuestión de la legitimación activa resulta de interés recordar que la Directiva 2007/66/CE de 11 de diciembre de 2007, por la que se modifican las Directivas 89/665/CEE, impone a los Estados simplemente un mínimo en materia de legitimación:

“Artículo 1.3. Los Estados miembros velarán porque, con arreglo a modalidades detalladas que ellos mismos podrán determinar, los procedimientos de recurso sean accesibles, como mínimo, a cualquier persona que tenga o haya tenido interés en obtener un determinado contrato y que se haya visto o pueda verse perjudicada por una presunta infracción." 
Ha de analizarse la legitimación para interponer el recurso especial a la vista de los principios de la contratación pública comunitaria de libertad de acceso a las licitaciones, publicidad, transparencia e igualdad. En este sentido es elocuente la sentencia del TJCE de 14 de junio de 2003 C-249/01 (citada en otras posteriores), que señala:

"17. A este respecto, basta recordar que, en virtud del artículo 1, apartado 3, de la Directiva 89/665, los Estados miembros deben garantizar que los procedimientos de recurso previstos por dicha Directiva sean accesibles "como mínimo" a cualquier persona que tenga o haya tenido interés en obtener un determinado contrato público y que se haya visto o pueda verse perjudicada por una presunta infracción del Derecho comunitario en materia de contratos públicos o de las normas nacionales de adaptación al citado Derecho.

18. De lo anterior resulta que esta disposición no obliga a los Estados miembros a garantizar que dichos procedimientos de recurso sean accesibles a cualquier persona que desee obtener la adjudicación de un contrato público, sino que les permite exigir que, además, la persona interesada se haya visto perjudicada o pueda verse perjudicada por la infracción que alega.

19. Por lo tanto, procede responder a la primera cuestión que el artículo 1, apartado 3, de la Directiva 89/665 no se opone a que los procedimientos de recurso previstos por dicha Directiva sólo sean accesibles a las personas que desean obtener la adjudicación de un contrato público determinado si éstas se han visto o pueden verse perjudicadas por la infracción que alegan."

Como se ve en los considerandos jurídicos transcritos, la Directiva comunitaria (la regulación inicial de esta cuestión en el art. 3.1 de la Directiva 89/665/CEE, no ha variado en este aspecto en el art. 1.3 de la Directiva 2007/66), sólo impone la obligación de hacer accesibles los recursos a cualquier persona que reúna los siguientes requisitos:

1. Que tenga o haya tenido interés en obtener un determinado contrato público.

2. Que se haya visto o pueda verse perjudicado por una presunta infracción en materia de contratación pública.

En esta línea, el Tribunal de Justicia de las Comunidades Europeas ha declarado que debe ser posible que una empresa interponga un recurso directamente contra las características discriminatorias de la licitación, sin esperar a que concluya el procedimiento de adjudicación del contrato (apartado 30), pero que carece de legitimación activa para impugnar la adjudicación del contrato una persona que, estimando discriminatorias las cláusulas de una licitación, no impugna ésta ni presenta oferta (STJCE de 12 de febrero de 2004 [ TJCE 2004, 37], C-230/02, Grossmann Air Service).

Con carácter general, la doctrina del TJCE sobre este recurso puede resumirse en que los procedimientos de recurso deben ser, por una parte, eficaces y los más rápidos posible y, por otra, accesibles a cualquier persona que tenga o haya tenido interés en obtener un determinado contrato público y que se haya visto o pueda verse perjudicado por una presunta infracción (STJCE de 15 de mayo de 2003 [TJCE 2003, 138], Comisión/España, apartado 78).

La transposición que de la norma comunitaria hace la LCSP tanto en el antiguo artículo 37.3 del TRLCSP como en el vigente artículo 42 del TRLCSP, parecen abrir una legitimación amplia en materia de contratación, aunque no se establece, al menos expresamente una "acción pública", como existe, por ejemplo, en urbanismo o en medio ambiente ${ }^{2}$.

Es por ello necesario precisar el alcance de la legitimación para recurrir en materia de contratación a la vista de la jurisprudencia española, quién se considera por ésta que está legitimado para interponer un recurso en materia de contratación. En esta línea señala la doctrinaª que en relación con la legitimación, “se recoge una legitimación amplia, acorde con las previsiones de la Directiva 89/665/CEE”, que debe ser interpretada de acuerdo con la doctrina jurisprudencial al respecto.

2 En el mismo sentido, se pronuncia Gallego Córcoles, I., "Legitimación para instar la revisión de decisiones en materia de contratación pública”, Contratación Administrativa Práctica, № 75, Sección Informe de Jurisprudencia, Editorial La Ley, mayo 2008, pág. 47, que recuerda en este sentido que ya "la STS de 11 de febrero de 2003 (...) declara que (...) salvo en los supuestos en que el ordenamiento reconoce legitimación para ejercer la acción pública, no basta como elemento legitimador el genérico deseo ciudadano de la legalidad, pues es necesaria una determinada relación con la cuestión debatida". En el mismo sentido, la misma autora en la obra colectiva “Contratación del Sector Público Local”, edit. La Ley-El Consultor, $2^{a}$ edición 2010, págs. 336-347. La inexistencia de una “acción pública” se mantiene en el Acuerdo 44/2012, de 9 de octubre de 2012, del Tribunal Administrativo de Contratos Públicos de Aragón, aunque se admite una legitimación amplia.

3 Noguera de la Muela, B., "El recurso especial en materia de contratación y las medidas cautelares en la Ley 30/2007, de 30 de octubre, de Contratos del Sector Público, a la vista de la Directiva 2007/66/CEE, por la que se modifica la directiva 89/665/CEE", Noticias de la Unión Europa $n^{\circ} 298,2009$, págs. 95 a 111. En concreto esta autora cita la sentencia del Tribunal Constitucional 119/2008, de 13 de octubre de 2008, que ampara el derecho de un empresario a recurrir una licitación aunque no haya tomado parte en ella. 
Analizamos la doctrina jurisprudencial, al hilo de los trabajos publicados sobre esta cuestión por Vázquez Matilla, Ballesteros Moffa, Gallego Córdoles y Díez Sastre ${ }^{4}$, donde abordan las posibilidades de recurso en las denominadas actuaciones precontractuales, referidas a la preparación y adjudicación del contrato. En el régimen de la legitimación activa establecido en las leyes procesales, el factor clave -amén de la titularidad de un derecho- es la noción de "interés legítimo" (art. 19.1.a) LJCA). En su aplicación se ha elaborado una detallada jurisprudencia del Tribunal Constitucional, del Supremo, y de los Tribunales Superiores de Justicia, sobre las personas legitimadas para impugnar las decisiones en materia de contratos públicos ante la jurisdicción contencioso-administrativa, cuya doctrina puede extractarse en las conclusiones siguientes:

- Para que exista un interés legítimo la resolución impugnada (o la inactividad denunciada) debe repercutir de manera clara y suficiente en la esfera jurídica de quien acude al proceso (STS de 14 de octubre de 2003, y del TC las siguientes sentencias: núms. 197/8, 99/89, 91/95, 129/95, 123/96 y 129/2001, entre otras).

— La regla general es que sólo pueden impugnar decisiones en materia contractual las personas que participaron en la licitación. Así se recoge en la STS de 20 de julio de 2005 (RJ 2005, 6526), y en el caso de recursos contra los actos de adjudicación contractual, por ejemplo, en la STS de 17 de mayo de 2005 (RJ 2005, 6370). Quien no ha presentado proposición alguna ni ha tenido por tanto participación alguna en la licitación carece de interés legítimo y, en consecuencia, no está legitimado para recurrir la adjudicación del contrato (así lo declara la STS de 10 de julio de 2006 (RJ 2006, 7225). Tampoco lo está quien participa en una licitación sin recurrir los pliegos e impugna el procedimiento cuando no resulta adjudicatario, pues se trataría de actos consentidos, yendo en contra de los actos propios (salvo cuando el vicio que se alega sea de nulidad de pleno derecho) 5 .

- Se admite como matización la legitimación para impugnar la convocatoria o el pliego de quien, teniendo interés legítimo, no ha participado en el concurso y su posible irradiación a la adjudicación posterior, en caso de que hubiese recurrido esos actos administrativos. En este sentido pueden verse las STS de 5 de julio de 2005 (RJ 2005, 5205) y STS de 29 de junio de 2006 (RJ 2006, 7054).

- También la jurisprudencia ha reconocido interés legítimo, y con ello legitimación activa para impugnar convocatorias y pliegos de licitación de contratos públicos, a determinadas entidades que ni participaron en la licitación, ni eran licitadores potenciales, por tratarse de organizaciones representativas de intereses económicos, sociales o profesionales que actúan en beneficio de sus asociados. Así se admite, por ejemplo, en las STS de 15 de marzo de 2004 (RJ 2004, 3667), Sentencia de la Sala de lo Contencioso-Administrativo del TSJ de Castilla-La Mancha núm. 238/2007, de 24 de mayo (RJCA 2007, 604). Resulta más conflictiva la admisión de la legitimación activa de los sindicatos, si no se demuestra que las resoluciones conculcan los interés económicos o los derechos laborales de los representados (así deniega esa legitimación la STS de 8 de marzo de 2005 (RJ 2005, 1784), y en la Resolución de 8 de junio de 2011 del Tribunal Administrativo de Contratación Pública de la Comunidad de Madrid).

El acceso al proceso es una vertiente del derecho constitucional a la tutela judicial efectiva del artículo 24 de la Constitución (RCL 1978, 2836). Por ello también ha de analizarse la doctrina del Tribunal Constitucional sobre la legitimación para recurrir actos relativos a contratos públicos con ocasión de recursos de amparo fundados en la infracción de aquel derecho fundamental. La STC 119/2008, de 13 de octubre (RTC 2008, 119) afirma que la participación en el proceso de licitación no es condición imprescindible para estar legitimado para impugnar la convocatoria o el pliego, entendiendo que no se puede negar la existencia de "un interés legítimo de la recurrente que le otorgara legitimación en el proceso, por el mero hecho de no haber tomado parte en el concurso que tra-

$4 \quad$ Vázquez Matilla, F.J.: “Comentario a la sentencia del Tribunal de Justicia de las Comunidades Europeas de 3 de abril de 2008. La vulneración de la Directiva sobre recursos y su incidencia en la normativa sobre contratación administrativa en Navarra", Revista Jurídica de Navarra ISSN: 0213-5795, enero-junio 2008, № 45, págs. 149 a 181.

Ballesteros Moffa, L.A.:. "Comentario a la Ley 34/2010, de 5 de agosto, de modificación de las leyes de contratación pública en materia de recursos, y de la Ley de Jurisdicción Contencioso-Administrativa”, Justicia Administrativa, núm. 50, 2011, págs. 25 a 45.

Gallego Córdoles, I., en el trabajo ya citado "Legitimación para instar la revisión de decisiones en materia de contratación pública", Contratación Administrativa Práctica, №75, Sección Informe de Jurisprudencia, Editorial La Ley, mayo 2008 , pág. 47.

Díez Sastre, S., analiza el recurso especial en el artículo "El recurso especial en materia de contratación pública" Anuario de Derecho Municipal, $n^{\circ}$ 5, 2012, págs. 129 a 165; y en el marco de la más amplio de la defensa de los licitadores, La tutela de los licitadores en la adjudicación de contratos públicos, Marcial Pons, 2012.

Puede verse también la condena contra España del TJCE en relación con esta cuestión, Moreno Molina, J.A., “Recursos contra la adjudicación el contrato. Condena a España”, Contratación Administrativa Práctica N 76, 2008, páginas 20 a 26. Y sobre otra condena contra España antes del TRLCSP, en el trabajo de Ballesteros Arribas, S., "Condena al Reino de España por no haber extendido el sistema de recursos a las empresas públicas y por la necesidad de interponer recurso para que se puedan adoptar medidas cautelares", El Consultor de los Ayuntamientos y los Juzgados, N 17/2003, págs. 2962 a 2964.

5 Díez Sastre, S., “El recurso especial en materia de contratación pública”, Anuario de Derecho Municipal de 2011, n 5, Marcial Pons, pág. 144, argumenta con claridad este planteamiento, citando a otros autores que respaldan esta postura. Esta autora estima que sobre esta cuestión sería conveniente establecer una regulación legal más precisa y garante de la seguridad jurídica de los interesados ya que no siempre será sencillo detectar las posibles infracciones de las reglas de procedimiento antes de la presentación de las ofertas. 
taba de impugnar, sin haber ponderado las razones expuestas en la demanda contenciosa". Conculca su derecho al acceso a la tutela judicial efectiva, siendo necesario que se examinen las circunstancias del caso y verificar si la persona aduce en su recurso motivos que justifiquen la existencia de un interés legítimo, lo que habilita para la impugnación a los licitadores potenciales.

Esta doctrina constitucional coincide en buena medida con la jurisprudencia del Tribunal Supremo en la materia, que configura la exigencia de participación como una regla general, que ha de ser excepcionada cuando, en ausencia de ella, se acredita un interés legítimo en la impugnación. Ahora bien, el criterio de esta STC 119/2008 disipa algunas dudas y, en su caso, aplicaciones excluyentes del requisito de la participación, por lo que habrá de comprobarse caso por caso si, pese a no participar, se ostenta algún interés que justifique la impugnación.

En aplicación de toda esta doctrina jurisprudencial, el TRLCSP configura en su artículo 42 un recurso especial en materia de contratación abierto a las personas físicas y jurídicas cuyos derechos o intereses legítimos se hayan visto perjudicados o puedan resultar afectados. Así pues, el propio tenor literal del precepto muestra que se reconoce legitimación activa para recurrir no sólo a los que han participado en la licitación, pues los licitadores están siempre legitimados, sino también a otras personas que acrediten la titularidad de derechos o intereses legítimos que sean perjudicados o bien puedan ser afectados. Dicho con otras palabras, la legitimación activa para el recurso especial establecido en la LCSP es una legitimación amplia, que parece ir más allá del doble criterio comunitario de interés en obtener el contrato y de perjuicio, y debe interpretarse de acuerdo con el criterio extenso tanto del TJCE como del Tribunal Supremo y del Tribunal Constitucional, de modo que la participación en la licitación no es condición inexcusable para ostentar un interés legítimo que otorgue legitimación activa para interponer el recurso especial en materia de contratación, por lo que alcanza también a los licitadores potenciales.

La existencia de una legitimación amplia para la interposición del recurso especial en materia de contratación se ha reconocido en la Resolución 122/2012 del Tribunal Administrativo Central de Recursos Contractuales, y en el mismo sentido la Resolución 11/2011 del Tribunal Administrativo de Contratación Pública de la Comunidad de Madrid. El Acuerdo 44/2012, de 9 de octubre de 2012, del Tribunal Administrativo de Contratos Públicos de Aragón acoge también esta interpretación, sintetizando la doctrina del Tribunal Constitucional, defendiendo que hay "interés legítimo" siempre que exista una relación material entre el sujeto y el objeto de la pretensión, de modo que su anulación produzca automáticamente en su esfera patrimonial un efecto positivo o negativo actual o futuro, pero cierto, debiendo entenderse tal relación referida a un interés en sentido propio, cualificado, específico, actual y real. (STC 52/2007, de 12 de marzo, FJ3 y 119/2008, de 13 de octubre).

En suma, están legitimados los licitadores, los perjudicados y los potencialmente afectados en sus derechos o intereses legítimos por el acto impugnado, pero no cualquier persona interesada en la salvaguarda genérica de la legalidad o de los recursos públicos, no existe una acción pública en materia contractual. Es decir, y pese a resultar reiterativo, sólo están legitimados para interponer el recurso especial en materia de contratación los licitadores que hayan participado en el correspondiente procedimiento para la adjudicación del contrato de que se trate, aquellos que hubiesen podido concurrir a la licitación si las limitaciones excesivas establecidas en los pliegos no los hubiesen excluido, y en general los contratistas que pudieron ser licitadores y se ven perjudicados por alguno de los actos previos a la formalización del contrato, así como las asociaciones de interés general que tengan como finalidad la defensa de los intereses de los potenciales participantes en la contratación que se recurre.

Pero no hay un legitimación abierta a cualquier persona o entidad en defensa de intereses generales o de la legalidad en general, si no tienen un interés legítimo y directo en la adjudicación del contrato de que se trate, si no tiene o ha podido tener interés en obtener un determinado contrato y que se haya visto o pueda verse perjudicada por una presunta infracción en materia de contratación. La acción pública para que cualquier persona pueda impugnar un acuerdo administrativo (o la inactividad de la Administración) por el mero interés en garantizar la legalidad, sólo es posible en los campos en los que legalmente se abre de forma expresa esta posibilidad. En este sentido resulta bien elocuente la STS de 11 de febrero de 2003, que declara que los Diputados y Senadores no están legitimados activamente para impugnar la adjudicación de un contrato administrativo, pues para que exista un interés legítimo en la jurisdicción contencioso administrativa, la resolución impugnada debe repercutir de manera clara y suficiente en la esfera jurídica de los recurrentes. Y con este criterio, la Resolución de 1 de junio de 2011 del Tribunal Administrativo de Contratación Pública de la Comunidad de Madrid rechaza la legitimación de los usuarios del servicio objeto del contrato ${ }^{6}$, y la Resolución 211/2012 del TACR niega la legitimación a quien no acredita representación de los trabajadores a quien dice defender y apela a un interés general7.

6 Se trataba de alumnos y madres de alumnos de una escuela de música.

7 Según esta Resolución de 30 de mayo de 2012, el recurrente alegaba "defender derechos de determinados trabajadores, sin citar dicha representación, e igualmente se atribuye competencias para la defensa general de intereses públicos". 
Además de esta legitimación de los particulares, entendemos que debe admitirse la legitimación de los miembros de la Corporación que hubiesen votado en contra de los actos o acuerdos recurridos o que no hayan podido participar en los órganos que hayan tomado la decisión cuestionada, legitimación que deriva no tanto de la doctrina analizada, como de la regulación expresa al efecto del artículo 63 de la LBRL. Esta legitimación se reconoce expresamente en el citado Acuerdo 44/2012, de 9 de octubre de 2012, del Tribunal Administrativo de Contratos Públicos de Aragón, que avala la afirmación con la cita de las STC 173/2004, de 18 de octubre, 108/2006, de 3 de abril y 210/2009, de 26 de noviembre, que reconocen una cobertura constitucional a los miembros de las corporaciones locales para el ejercicio adecuado del "ius officium" del que son titulares, de manera que dicha potestad se pueda ejercer sin trabas ante los órganos judiciales cuando su actuación está dirigida a la satisfacción de las necesidades y aspiraciones de la comunidad vecinal a la que representan, como es la de procurar que el ente local adecue su funcionamiento al ordenamiento jurídico. No obstante, la Resolución de 15 de junio de 2011 del Tribunal Administrativo de Contratación Pública de la Comunidad de Madrid rechaza en cambio la legitimación de un grupo municipal, si bien este había orientado el recurso en defensa de los empleados del servicios que se contrata, defensa que dice el Tribunal no le corresponde a los ediles recurrentes.

\section{Referencia especial al recurso por parte de licitadores que concurren en UTE}

La participación en las licitaciones públicas de varias empresas constituidas en unión temporal de empresas es muy habitual. Es evidente que como licitador, una UTE estará legitimada activamente para interponer un recurso especial en materia de contratación en cualquier procedimiento de adjudicación en el que participe.

Recordemos que una unión temporal de empresas funciona a efectos de participación en una contratación pública, como una "comunidad de bienes" y que la jurisprudencia reconoce legitimación activa a cualquiera de los partícipes o comuneros, con la única consecuencia de que la sentencia dictada en su favor aprovecha a los demás, $\sin$ que les perjudique la adversa o contraria. Así se reconoce en la sentencias del Tribunal Supremo de 13 de mayo de 2008 (RJ 2008, 5040), dictada en el recurso de casación 1827/2006, y 23 de julio de 2008 (RJ 2008, 4509), pronunciada en el recurso de casación 1826/2006. Ponen de relieve dichas sentencias "que la referida agrupación empresarial, aunque no constituida aún como persona jurídica, sí constituye una comunidad de bienes, derechos e intereses, dada la cotitularidad que ostentan sus miembros sobre los derivados del hecho de la presentación al concurso".

La duda puede plantearse en cuanto si el recurso ha de ser interpuesto por todos los integrantes de la UTE o pueden, por el contrario, interponerlo alguno de ellos y otros no o, incluso, si una vez interpuesto el recurso por el representante de la unión temporal, puede continuar al recurso pese a que alguno de los integrantes de la misma decida individualmente desistir del recurso.

La cuestión se aborda con precisión en la sentencia del Tribunal Supremo de 22 de junio de 2009 (Sala de lo contencioso administrativo sección $4^{\mathrm{a}}$, recurso de casación $n^{\circ}$ 5822/2007). Esta sentencia analiza la legitimación activa de un recurrente integrado en una UTE, examinando la doctrina jurisprudencia del propio Tribunal. Establece el Tribunal la conclusión de que el recurso interpuesto por parte de los integrantes de una UTE es admisible cuando se realiza "sin oposición de los restantes", pero no cuando expresamente alguno de los integrantes de la UTE muestra su oposición clara a la interposición de cualquier recurso jurisdiccional. Y ello porque en este caso, ante la eventual anulación del acto recurrido, nos encontraríamos ante "la patente inexistencia de la unión temporal de empresas que concurrió al concurso dada la renuncia de uno de sus integrantes"§. Otra cosa sería la posible reclamación de indemnización por daños y perjuicios que las restantes empresas que concurrieron en UTE pudieran reclamar contra la entidad que a la hora de recurrir se separa del criterio mayoritario y desiste de dicho recurso. Recogemos a continuación el fundamento jurídico sexto de esta sentencia:

"Esta Sala y Sección en supuestos como los examinados en las STS de 28 de febrero de 2005 (RJ 2005, 3453), 11 de julio de 2006 (RJ 2006, 8471), 13 de mayo (RJ 2008, 5042) y 23 de julio de 2008 (RJ 2008,4509 ) entiende procedente el ejercicio de acciones por uno de los miembros que componen la asociación empresarial. Presentan la particularidad de evidenciar una voluntad común de los integrantes aunque la interposición del recurso jurisdiccional fuere individual.

Sin embargo en el supuesto objeto aquí de recurso de casación no cabe aceptar la pretensión de la recurrente respecto a que el caso concernido fuere similar al enjuiciado en la STS de 28 de febrero de 2005 (RJ 2005, 3453). Todo lo contrario. De los hechos reflejados en la antedicha sentencia no se colige la existencia de disidencia alguna entre los componentes de la agrupación temporal como aquí sí sucede. $Y$ tales hechos no pueden ser desgajados de la sentencia cuyo quebranto se invoca.

8 Véase Gallego Córdoles, I., en el trabajo anteriormente citado, donde parece mantener el criterio contrario, con base en las STS de 28 de febrero de 2005 y de 11 de julio de 2006, pero ambas sentencias son analizadas en la de 22 de julio de 2009, Ilegando a la conclusión expuesta. 
De la situación fáctica reflejada en la sentencia de instancia, así como de la argumentación de la administración oponiéndose al recurso, queda patente que la otra empresa componente de la agrupación temporal renunció, anticipadamente, al ejercicio de cualquier acción judicial. Desistimiento que también realizó la persona física designada por todos los componentes de la asociación temporal de empresas para su representación en las actuaciones a llevar a cabo.

Por ello, debe aplicarse, mas "a sensu contrario" la doctrina plasmada en las sentencias de 13 de mayo (RJ 2008, 5042) y 23 de julio de 2008 (RJ 2008, 4509) que expresan que tal actuación de los coparticipes es admisible cuando se realiza "sin oposición de los restantes". $Y$ si aquí consta expresamente que uno de los componentes mostró su oposición clara a la interposición de cualquier recurso jurisdiccional es obvio que la Sala de instancia no ha quebrantado el conjunto de preceptos esgrimidos.

Y, por lo mismo, tampoco se ha conculcado la doctrina sobre los intereses legítimos ya que la eventual anulación del acto ningún beneficio reportaría a los recurrentes ante la patente inexistencia de la unión temporal de empresas que concurrió al concurso dada la renuncia de uno de sus integrantes".

El Tribunal Supremo considera que nuestro ordenamiento jurídico concede la legitimación activa a los integrantes de Uniones Temporales de Empresas de un modo amplio e independiente, a diferencia de otros ordenamientos jurídicos comunitarios como el belga (citado en la STS de 22 de julio de 2009, en referencia a la STJCE de 8 de septiembre de 2005) que exigen expresamente que la totalidad de los miembros de una unión temporal de empresas sin personalidad jurídica, que haya participado como tal en un procedimiento de adjudicación de un contrato público y a la que no se haya adjudicado ese contrato, ha de interponer el recurso contra la decisión de adjudicación, y no sólo de sus miembros a título individual. Pero, sin perjuicio de esa mayor amplitud, la meritada STS de 22 de julio de 2009 deja claro que si alguna de las empresas que integran una UTE se manifiesta expresamente en contra de la interposición del recurso, no puede continuar el recurso el resto de integrantes de la unión temporal, precisamente porque dicha unión ya no existe, y si finalmente se resolviese el recurso en favor de la UTE y se le adjudicase el contrato, no se podría formalizar el contrato cuando una de las empresas ya se mostró contraria a mantener una unidad de acción con el resto.

EI TJCE considera, efectivamente, que una normativa restrictiva en este sentido es compatible con las Directivas comunitarias sobre contratación pública (sentencia citada de 8 de septiembre de 2005, asunto C-129/04). Esta doctrina del TJCE se reitera, en las conclusiones del Abogado General Sr. Paolo Mengozzi presentadas el 27 de enero de 2011 y acogidas por la STJCE de 9 de junio de 2011 (Asunto C-401/09 P):

\begin{abstract}
“33. En este contexto, el Tribunal de Justicia consideró compatibles con el Derecho comunitario tanto una norma nacional que admitía únicamente el recurso interpuesto por la totalidad de los miembros de una unión temporal de empresas, (9) como una norma que, al contrario, permitía la interposición de un recurso por una sola empresa asociada. (10) Ello es así en la medida en que la Directiva 89/665 se limita a establecer "Ios requisitos mínimos a los que deben responder los procedimientos de recurso establecidos en los ordenamientos jurídicos nacionales con el fin de garantizar el respeto de las disposiciones del Derecho comunitario en materia de contratos públicos". (11)
\end{abstract}

34. En cambio, en materia de resarcimiento de daños y perjuicios, se considera que la existencia de un derecho de recurso individual para cada una de las empresas que constituyen una unión temporal viene exigido por el Derecho de la Unión. (12)."

Pero este planteamiento no es el que se establece en el ordenamiento jurídico español como se ha analizado, ya que se admite que cualquier miembro de una UTE está legitimado para interponer el recurso especial, siempre y cuando alguna otra de las empresas que integran la UTE no manifieste expresamente estar en contra de la interposición del recurso, en cuyo caso decaería la legitimación activa de los recurrentes.

\title{
4. Ámbito OBJETIVO Y SUBJETIVO de APLICACIÓN DEL RECURSO ESPECIAL EN MATERIA DE CONTRATACIÓN
}

De acuerdo con lo establecido en el artículo 40 del TRLCSP y en la Directiva 2007/66/CE, sólo son objeto de este recurso especial los contratos celebrados por entidades que tengan la consideración de poderes adjudicadores comprendidos en las categorías 17 a 27 del Anexo II de la Ley cuyo valor estimado sea igual o superior a 200.000 euros; los contratos de gestión de servicios públicos en los que el presupuesto de gastos de primer establecimiento, excluido el importe del Impuesto sobre el Valor Añadido, sea superior a 500.000 euros y el plazo de duración superior a cinco años; y los contratos sometidos a regulación armonizada: los contratos de colaboración entre el sector 
público y el sector privado, los contratos de obras y concesión de obra pública de cuantía superior a 5.000.000 €, los contratos de servicios comprendidos en las categorías 1 a 16 del Anexo II de esta Ley cuyo valor estimado sea igual o superior a 200.000 euros, y los de suministros también por encima de esa cantidad, cifras que se reducen en los contratos de suministros y servicios a $130.000 €$ cuando son celebrados por la Administración del Estado (y Entidades Gestoras y Servicios Comunes de la Seguridad Social) ${ }^{9}$. También serán susceptibles de este recurso los contratos subvencionados a que se refiere el artículo 17 del TRLCSP, es decir, aquéllos contratos subvencionados sometidos igualmente a regulación armonizada. No procederá este recurso en relación con los procedimientos de adjudicación que se sigan por el trámite de emergencia regulado en el artículo 113 del TRLCSP (art. 40.4 del TRLCSP).

Las CCAA de Navarra y Baleares ${ }^{10}$, han ampliado en su legislación específica el ámbito objetivo de este recurso especial a en todos los contratos. Más recientemente se ha sumado a esta ampliación de los contratos susceptibles de este recurso, aunque no para todos los contratos, la Comunidad Autónoma de Aragón ${ }^{11}$, incluyendo dentro de la competencia del Tribunal Administrativo de Contratos Públicos de Aragón, el conocimiento y resolución de los recursos especiales en materia de contratación en relación con los contratos de obras de importe superior a 1.000 .000 de euros y de suministros y servicios de más de 100.000 euros, al considerar que estos contratos tienen trascendencia comunitaria. Esta ampliación objetiva que se valora muy positivamente en cuanto beneficia a los pequeños y medianos contratistas y salvaguarda mejor los principios comunitarios de igualdad y extensión de los mismos a todos los contratos públicos ${ }^{12}$.

Contra los contratos administrativos no sujetos a regulación armonizada, el artículo 40.5, párrafo segundo del TRLCSP dispone que:

"Los actos que se dicten en los procedimientos de adjudicación de contratos administrativos que no reúnan los requisitos del apartado 1, podrán ser objeto de recurso de conformidad con lo dispuesto en la Ley 30/1992, de 26 de noviembre, de Régimen Jurídico de las Administraciones Públicas y del Procedimiento Administrativo Común, y en la Ley 29/1998 de 13 de julio, reguladora de la Jurisdicción Contencioso Administrativa".

Este recurso es también aplicable a los contratos de naturaleza no administrativa celebrados por las Administraciones Públicas, pues los acuerdos adoptados por el órgano de contratación con respecto a estos contratos son actos administrativos sujetos a los recursos de la LRJyPAC.

Esta nueva regulación legal recoge la opinión de la Junta Consultiva de Contratación Administrativa del Estado manifestada en el Informe 48/08, de 29 de enero de 2009, que analiza los recursos que proceden en la adjudi-

9 Los datos numéricos son los que derivan del Reglamento (UE) № 1251/2011 de la Comisión de 30 de noviembre de 2011 , incorporado a nuestro derecho interno por Orden EHA/3479/2011, de 19 de diciembre, por la que se publican los límites de los distintos tipos de contratos a efectos de la contratación del sector público a partir del 1 de enero de 2012.

Sobre la interpretación del concepto de gastos de primer establecimiento la encontramos en el Acuerdo 44/2012 de 9 de octubre de 2012 del Tribunal Administrativo de Contratos Públicos de Aragón (cuya lectura se recomienda en caso de tratarse el recurso a interponer frente a pliegos de contratos de gestión pública, cuya aprobación anula), indicando difiere notablemente del tecnicismo contable que los equipara a gastos inmateriales amortizables y que está formado por todos aquellos necesarios para poner en funcionamiento el servicio públicos, que deben diferenciarse de los gastos de explotación. Sin ánimo de una lista exhaustiva, pueden citarse como conceptos a incluir los siguientes: gastos en obra de inversión que corran a cargo del contratista, gastos en instalaciones nuevas o de reposición existentes, inversión en maquinaria de todo tipo, etc. Es decir, se incluyen las inversiones precisas para pone en funcionamiento el servicio público, excluyendo los gastos de explotación futuros y las inversiones futuras. Su determinación ha de buscarse en el anteproyecto de explotación.

10 La Ley $3 / 2003$, de 26 de marzo, de régimen jurídico de la Administración de la Comunidad Autónoma de las Illes Balears, regula en su artículo 66 un recurso administrativo especial en materia de contratación de carácter potestativo y que sustituye al de reposición, residenciando la competencia para resolverlo en la Junta Consultiva de Contratación Administrativa de esa Comunidad autónoma. Este recurso estaba previsto para todos los contratos, tanto en los sometidos a regulación armonizada como a los que no lo están por su cuantía o naturaleza. Pero de acuerdo con esa Junta Consultiva, ese recurso no es el recurso especial creado por la Ley 34/2010, por lo que la normativa balear está pendiente de adaptación al sistema de recursos especial del TRLCSP, si bien continúa vigente su recurso administrativo para los contratos y actos en las fases de ejecución, cumplimiento y extinción de los contratos, que no son objeto del recurso especial regulado en el TRLCSP.

La posibilidad de atribuir la resolución de estos recursos a las Juntas Consultivas de Contratación, dada su especialidad, fue propuesta por algunos autores como Ballesteros Moffa, L.A., en el trabajo “Comentario a la Ley 34/2010, de 5 de agosto, de modificación de las leyes de contratación pública en materia de recursos, y de la Ley de Jurisdicción Contencioso-Administrativa”, Justicia Administrativa, núm. 50, 2011, pág. 45. En esta línea la CCAA de Aragón, en la modificación por la Ley 3/2012, de 8 de marzo, de su Ley 3/2011 de 24 de febrero, de medidas en materia de Contratos del Sector Público de Aragón, prevé un recurso a las modificaciones de los contratos, en su artículo 12.bis.

11 La Ley 3/2012, de 8 de marzo, de medidas fiscales y administrativas de la Comunidad Autónoma de Aragón, modifica el artículo 17 de la Ley 3/2011, y concreta el ámbito objetivo de actuación del Tribunal Administrativo de Contratos Públicos de Aragón con la ampliación señalada.

12 Bernal Blay, M.A., "Aspectos orgánicos del recurso especial en materia de contratación pública en las comunidades autónomas”, publicado en “Cuadernos de Derecho Local” (QDL), de la Fundación Democracia y Gobierno Local, junio, 2011, págs. 14 y 15. Aboga también por esta ampliación del ámbito objetivo del recurso especial Ballesteros Moffa, L.A., en "Comentario a la Ley 34/2010, de 5 de agosto, de modificación de las leyes de contratación pública en materia de recursos, y de la Ley de Jurisdicción Contencioso-Administrativa", Revista Justicia Administrativa, núm. 50, 2011, pág. 48, y en La adjudicación de contratos en el sector público, Thomson-Civitas, Navarra, 2010, págs. 235 y ss. 
cación provisional de contratos no sometidos a regulación armonizada. Afirma la Junta que sólo pueden interponerse los recursos previstos en la Ley de Régimen Jurídico de las Administraciones Públicas y del Procedimiento Administrativo Común, remitiéndose al artículo 107 de esta Ley, que establece que, "Contra las resoluciones y actos de trámite, si estos últimos deciden directa o indirectamente el fondo del asunto, determinan la imposibilidad de continuar el procedimiento, producen indefensión o perjuicio irreparable a derechos e intereses legítimos, podrán interponerse por los interesados los recursos de alzada y potestativo de reposición". Generalmente será el recurso de potestativo de reposición el procedente como previo al contencioso administrativo, pues por regla general las resoluciones dictadas por los órganos de contratación ponen fin a la vía administrativa.

En cuanto a los contratos celebrados por otras entidades del sector público que no sean Administraciones Públicas ni poderes adjudicadores, podrá establecerse en los pliegos el sometimiento de las cuestiones litigiosas a un sistema de arbitraje de acuerdo con la Ley 60/2003, de 23 de diciembre, de Arbitraje, según establece el artículo 50 del TRLCSP. A estos efectos se ha creado el Tribunal de Arbitraje para la Contratación Pública (TACOP), que es una institución arbitral constituida en el seno de la Asociación Europea de Arbitraje (AEADE). Este Tribunal, configurado como un comité especializado de la AEADE, está llamado a conocer de las controversias relativas a la ejecución, modificación y extinción de los contratos adjudicados por entes, organismos o entidades del sector público que no tengan carácter de Administraciones públicas, de conformidad con lo dispuesto en el artículo 50 del TRLCSP. Incluye, por lo tanto, la totalidad de las entidades públicas empresariales y sociedades públicas, así como un diverso grupo de entes del sector público, que actúan contractualmente en régimen de derecho privado, vinculados a la Administración General del Estado, a las Comunidades Autónomas y a todas las Entidades Locales. Los miembros del TACOP responden a un principio de excelencia técnica, estando integrado por juristas de reconocido prestigio y acreditada experiencia profesional en el ámbito del Derecho Administrativo y la contratación del sector público.

El ámbito material del recurso especial en materia de contratación o, lo que es lo mismo, las cuestiones que pueden ser objeto del recurso especial en materia de contratación, es decir, las que podrían ser objeto de alegación en esta fase procedimental, son exclusivamente las que se establecen en el artículo 40.2 del TRLCSP:

“2. Podrán ser objeto del recurso los siguientes actos:

a) Los anuncios de licitación, los pliegos y los documentos contractuales que establezcan las condiciones que deban regir la contratación.

b) Los actos de trámite adoptados en el procedimiento de adjudicación, siempre que éstos decidan directa o indirectamente sobre la adjudicación, determinen la imposibilidad de continuar el procedimiento o produzcan indefensión o perjuicio irreparable a derechos o intereses legítimos. Se considerarán actos de trámite que determinan la imposibilidad de continuar el procedimiento los actos de la Mesa de Contratación por los que se acuerde la exclusión de licitadores.

c) Los acuerdos de adjudicación adoptados por los poderes adjudicadores.

Sin embargo, no serán susceptibles de recurso especial en materia de contratación los actos de los órganos de contratación dictados en relación con las modificaciones contractuales no previstas en el pliego que, de conformidad con lo dispuesto en los artículos 105 a 107, sea preciso realizar una vez adjudicados los contratos tanto si acuerdan como si no la resolución y la celebración de nueva licitación.”’3

Dicho en palabras del TJCE, sólo pueden ser objeto de este recurso las "decisiones hayan infringido el Derecho comunitario en materia de contratación públicos o las normas nacionales de incorporación de dicha normativa" (art. 1.1.3 de la Directiva 2007/66; (STJCE de 14 de junio de 2003, Asunto C-249/01) STJCE de 28-10-1999, asunto C-81/98 y STJCE 23-01-2003, Asunto C-75/01).

De este modo, puede ser objeto de este recurso una propuesta de adjudicación en la que, por ejemplo, se rechazara una oferta presentada por un licitador por considerar que la misma es temeraria, puesto que se trata de un acto de trámite adoptado en el procedimiento de adjudicación, que decide directamente sobre la adjudicación y que determine la imposibilidad de continuar el procedimiento (art. 40.2.b del TRLCSP). Por el mismo motivo, pueden ser objeto de recurso las decisiones previas de la Mesa que supongan la admisión o rechazo de licitadores a un procedimiento; o las decisiones del órgano de contratación al aprobar los pliegos con requisitos de capacidad, clasificación o solvencia excesivamente restrictivos de la competencia en relación con el objeto y cuantía del con-

13 Párrafo introducido en la LCSP por la Ley 24/2011, de 1 de agosto, de contratos del sector público en los ámbitos de la defensa y de la seguridad, Disposición final primera. Ocho, con la referencia a los artículos 92 bis a 92 quáter del TRLCSP. 
trato de que se trate. De la misma manera, pueden ser objeto de recurso los acuerdos de adjudicación cuando se considere que no han sido aplicados correctamente los criterios de valoración del pliego, pero no si se rechaza en esta fase un criterio de valoración que se considere que no cumple con las exigencias del artículo 136, ya que debió recurrirse con anterioridad por quien ahora no se ha visto favorecido por el mismo y lo recurre.

Respecto de los defectos de tramitación distintos de los relacionados en el artículo 40.2 del TRLCSP, el apartado siguiente de este mismo precepto establece al respecto que, "podrán ser puestos de manifiesto por los interesados al órgano al que corresponda la instrucción del expediente o al órgano de contratación, a efectos de su corrección, y sin perjuicio de que las irregularidades que les afecten puedan ser alegadas por los interesados al recurrir el acto de adjudicación". Por lo tanto, los defectos de tramitación que se pueden alegar en un recurso especial, sólo son recurribles los referentes a la fase del procedimiento de contratación en la que se encuentra el expediente, no a algún posible defecto de tramitación anterior que ya pudo haber sido recurrido en el momento procesal oportuno y que, o bien no fue impugnado en ese momento, o si lo fue, se desestimó, pues no se pueden abrir de nuevo vías impugnatorias para cuestiones ya resueltas, al menos, en sede administrativa.

Asimismo, la Ley 24/2011, de 1 de agosto, de contratos del sector público en los ámbitos de la defensa y de la seguridad, somete igualmente a los contratos celebrados en este ámbito dentro del objeto del recurso especial en materia de contratación:

Artículo 59 .

“1. Serán susceptibles de recurso, en los términos establecidos en los artículos 310 a 319 de la Ley 30/2007, de 30 de octubre, de contratos del sector público, los actos y trámites enumerados en esta última Ley ${ }^{14}$, de acuerdo con el apartado cuatro de este mismo artículo, cuando se refieran a los contratos regulados en esta Ley, siempre que, conforme a su artículo 5, estén sujetos a regulación armonizada. (...)

4. Podrán ser objeto de recurso los actos y trámites enumerados en el artículo 310.2 de la Ley 30/2007, de 30 de octubre, de contratos del sector público".

\section{5. ÓRGANO COMPETENTE PARA RESOLVER EL RECURSO ESPECIAL}

El artículo 37 del TRLCSP antes de la reforma de 2010, atribuía la resolución del recurso a un órgano, cuyas resoluciones agotaran la vía administrativa en el caso de contratos de una Administración Pública, órgano que en principio sería de la propia Administración que tramitase el contrato objeto del recurso, o al titular del departamento, órgano, ente u organismo al que esté adscrita la entidad contratante o al que corresponda su tutela, si ésta no tuviera el carácter de Administración Pública.

Sin embargo, la Ley 34/2010 determinó que la resolución de este recurso especial en materia de contratación se atribuya a nuevos órganos. Ello es una exigencia de la necesaria imparcialidad que la Directiva 2007/66/CE impone al órgano que ha de resolver estos recursos. Así, en el ámbito de la Administración del Estado, la resolución de este recurso se ha atribuido en la Ley 34/2010 a un nuevo órgano creado específicamente para este fin, el Tribunal Administrativo Central de Recursos Contractuales, tribunal administrativo independiente, adscrito al Ministerio de Economía y Hacienda. En el ámbito de las Comunidades Autónomas, serán éstas las que regularán los órganos que atenderán a dichos recursos especiales. Concretamente, el artículo 41.1.2 del TRLCSP establece la creación del Tribunal Administrativo Central de Recursos Contractuales, compuesto por un Presidente y un mínimo de dos vocales, si bien reglamentariamente se podrá incrementar el número de vocales que habrá de integrar el Tribunal cuando el volumen de asuntos sometidos a su conocimiento lo aconseje. No obstante, la creación orgánica de este Tribunal no implica que su funcionamiento se inicie de forma automática tras la entrada en vigor de la Ley (9 de septiembre de 2010), pues fue necesario antes seleccionar a sus miembros, para lo cual se abrió el correspondiente proceso de selección (BOE de 16 de agosto de 2010), si bien en la actualidad el mismo ya se ha constituido. Este Tribunal contará, al objeto de garantizar la eficacia del procedimiento de resolución de los recursos, con el apoyo técnico y administrativo de la Secretaría de la Junta Consultiva de Contratación Administrativa (Disposición Adicional $2^{\mathrm{a}}$ ), y se podrán constituir Tribunales Administrativos Territoriales de Recursos Contractuales con sede en cada una de las capitales de Comunidad Autónoma, en la medida en que las necesidades lo exijan (Disposición Adicional $\left.1^{\mathrm{a}}\right)$.

Asimismo, se ha creado el Tribunal de Recursos Contractuales de las Cortes Generales, a través de la reunión conjunta de 21 de diciembre de 2010 de las Mesas del Congreso de los Diputados y del Senado (BOE de 25 de enero de 2011) para resolver, conforme se indica en su artículo 1, el recurso especial en materia de contratación previo

14 Esta remisión se ha de entender hecha ahora a los artículos 40 a 50 del TRLCSP. 
a la interposición del recurso contencioso-administrativo establecido por la Ley de Contratos del Sector Público, el cual está compuesto, de acuerdo con su artículo 2, por un Diputado, un Senador y el Interventor de las Cortes Generales. A la vista de la composición de este Tribunal, puede cuestionarse que en este Tribunal concurra el imprescindible requisito de imparcialidad que exige la normativa comunitaria.

En cuanto a las Comunidades Autónomas, el artículo 41.3 del TRLCSP dispone que “(...) la competencia para resolver los recursos será establecida por sus normas respectivas, debiendo crear un órgano independiente cuyo titular, o en el caso de que fuera colegiado al menos su Presidente, ostente cualificaciones jurídicas y profesionales que garanticen un adecuado conocimiento de las materias de que deba conocer".

En tanto la Comunidad Autónoma respectiva no cree estos Tribunales, hay que tener presente el contenido de la disposición transitoria segunda de la Ley 34/2010, relativo al régimen supletorio para las Comunidades Autónomas, donde se indica que: "En tanto una Comunidad Autónoma no regule ante quién debe (...) interponerse el recurso contra los actos indicados en el artículo 310.1 y 2 de la primera o en el artículo 101.1 de la segunda, y que efectos derivarán de su interposición, serán de aplicación las siguientes normas: (...) b) La competencia para la resolución de los recursos continuará encomendada a los mismos órganos que la tuvieran atribuida con anterioridad".

Las Comunidades Autónomas están creando sus propios Tribunales (así, Madrid ${ }^{15}$, País Vas $\mathrm{CO}^{16}$, Cataluña ${ }^{17}$, Castilla y León, Aragón ${ }^{18} \mathrm{o}$ Andalucía ${ }^{19}$ ), aunque en todas el proceso parece lento, demora en parte impuesta

15 Ley 9/2010, de 23 de diciembre, de Medidas Fiscales, Administrativas y de Racionalización del Sector Público de Madrid crea en su artículo 3 el Tribunal Administrativo de Contratación Pública de la Comunidad de Madrid. El artículo 2. cuatro de esta Ley prevé una tasa por la realización de actividades competencia del Tribunal Administrativo de Contratación Pública de la Comunidad de Madrid.

16 En el País Vasco, la Ley 5/2010, de 23 de diciembre, aprueba los Presupuestos Generales del País Vasco, se crea el Tribunal como Órgano independiente de carácter unipersonal, que extenderá su actuación a la administración autonómica y a las administraciones locales de dicha Comunidad. Se prevé que los municipios de más de 50.000 habitantes puedan crear su propio órgano competente para la resolución de los recursos de su ámbito local y sector público respectivo, así como las Diputaciones Forales. La cualificación exigida para la persona que asuma este puesto es la misma que la prevista en el TRLCSP para el presidente del TACRC, aunque restringe a los posibles candidatos a que hayan desempeñado su actividad profesional en cualquiera de las administraciones públicas de esta Comunidad Autónoma.

17 El Acuerdo del Parlamento de Cataluña de 1 de marzo de 2011, de creación del Tribunal de Recursos Contractuales del Parlamento de Cataluña (DOGC de 28 de marzo de 2011). Asimismo, la Ley 7/2011, de 27 de julio, de medidas fiscales y financieras de Cataluña crea el órgano Administrativo de Recursos Contractuales de Cataluña, inicialmente con carácter de órgano unipersonal y se faculta a los municipios de más de 50.000 habitantes a crear sus propios Tribunales (disposición adicional cuarta.2 párrafo segundo).

Esta ley ha sido modificada por la Ley 5/2012, de 20 de marzo, de medidas fiscales, financieras y administrativas y de creación del impuesto sobre las estancias en establecimientos turísticos (DOGC de 23 de marzo).

Artículo 79. Modificación de la Ley 7/2011.- Se modifica el apartado 12 de la disposición adicional cuarta de la Ley 7/2011, de 27 de julio, de medidas fiscales y financieras, que queda redactado del siguiente modo:

“12. El estatuto personal del Órgano Administrativo de Recursos Contractuales de Cataluña es el siguiente:

a) Es designado por el titular o la titular del Departamento de la Presidencia. La resolución de nombramiento debe publicarse en el Diario Oficial de la Generalitat de Catalunya.

b) Está sujeto al mismo régimen de incompatibilidades que el correspondiente a los altos cargos de la Generalidad.

c) Las retribuciones que debe percibir se asimilan a las correspondientes al personal funcionario de la Administración de la Generalidad.

d) El nombramiento da lugar a la declaración de la situación administrativa de servicios especiales.

e) Es inamovible y su mandato tiene una duración de cinco años, a contar desde la toma de posesión, que debe tener lugar una vez publicado el nombramiento. El titular o la titular del Órgano puede ser reelegido por períodos sucesivos de la misma duración sin necesidad de realizar un proceso de selección nuevo".

La resolución de nombramiento debe establecer, de acuerdo con lo establecido por el apartado anterior, las retribuciones y el régimen jurídico del Órgano, y debe determinar las condiciones para sustituir al titular o la titular, en los supuestos de vacante, ausencia o enfermedad, en los términos del artículo 45 de la Ley 13/1989, de 14 de septiembre, de organización, procedimiento y régimen jurídico de la Administración de la Generalidad de Cataluña. La persona que lo sustituya debe reunir los mismos requisitos exigidos para la persona titular del Órgano y debe ejercer sus funciones en las mismas condiciones. El 1 de junio de 2012 entró en funcionamiento del Órgano Administrativo de Recursos Contractuales de Cataluña, según comunicó el 12 de junio de 2012 la Oficina de Supervisión y Evaluación de la Contratación Pública (OSACP).

18 En la Ley 3/2011, de 24 de febrero, de medidas en materia de Contratos del Sector Público de Aragón.

19 Decreto 332/2011, de 2 de noviembre, por el que se crea el Tribunal Administrativos de Recursos Contractuales de la Junta de Andalucía (BOJA de 11 de noviembre de 2011). De acuerdo con su artículo 1, este Tribunal sólo atenderá los recursos especiales contra los contratos de la Junta de Andalucía y sus entidades instrumentales que sean poderes adjudicadores. Para las Entidades Locales andaluzas se prevé en el artículo 10 de este Decreto la posibilidad de que creen su propios “órganos, especializados e independientes" para resolver el recurso especial. De manera aparentemente potestativa ("podrán”) se contempla que los Tribunales que creen las Diputaciones Provinciales conozcan y resuelvan los recursos administrativos especiales que se interpongan contra los contratos de los municipios a los que han de prestar su asistencia material (algo que estaba previsto en el anteproyecto de la Ley 34/2010, pero que se rechazó en la redacción final de la Ley antes la oposición de las Diputaciones). Se contempla también la posibilidad de que el Tribunal Administrativo de Recursos Contractuales de la Junta, pueda resolver los recursos especiales contra los contratos de las EELL andaluzas los poderes adjudicadores de ellas dependientes, mediante convenio individualizado con el Consejero de Hacienda (art. 10.3).

El art 10 del decreto 332/2011, de 2 de noviembre, por el que se creó el Tribunal Administrativo de Recursos Contractuales de la Junta de Andalucía, habilitaba que los entes locales podían crear sus propios Tribunales para el conocimiento de los recursos especiales, cuestiones de nulidad y reclamaciones en materia contractual. Así El Ayuntamiento de Granada, por acuerdo plenario de fecha veintiuno de diciembre de dos mil once ha adoptado, aprobó del Reglamento de funcionamiento del Tribunal Administrativo de Contratos Públicos de Granada (BOP de Granada de 29 de diciembre de 2011).

Por Orden de 14 de diciembre de 2011, se acuerda el inicio del funcionamiento del Tribunal Administrativo de Recursos Contractuales de 
por las restricciones presupuestarias que impone la coyuntura económica actual ${ }^{20}$. Así, por ejemplo, en la Comunidad de Castilla y León, la Ley 1/2012, de 28 de febrero, crea su Tribunal autonómico de Recursos Contractuales de esta Comunidad, adscrito al Consejo Consultivo, e integrado por sus mismos miembros, un proceso que había iniciado con la Ley 19/2010, de 22 de diciembre"21. Las CCA de Navarra y Baleares establecieron un sistema de recurso especial anteriormente a la Ley 34/201022. Otras CCAA y las Ciudades Autónomas se han acogido a la posibilidad que prevé el artículo 41.3, párrafos cuarto y quinto de suscribir un convenio con el Estado para atribuir la competencia para resolver los recursos especiales en materia de contratación que se produzcan en su ámbito al Tribunal Administrativo Central de Recursos Contractuales (La Rioja, Melilla, Extremadura, Castilla La Mancha' ${ }^{23}$.

En el caso de las Entidades Locales, al haberse rechazado la propuesta del anteproyecto de Ley de crear tribuales específicos en las Diputaciones Provinciales ${ }^{24}$, corresponderá a la normativa autonómica determinar el órgano competente para resolver estos recursos en aquellas CCAA que tengan atribuida competencia normativa y de ejecución en materia de régimen local y contratación; en el supuesto de que no exista previsión expresa en la legislación autonómica, la competencia corresponderá al mismo órgano al que las Comunidades Autónomas en cuyo territorio se integran las Corporaciones Locales hayan atribuido la competencia para resolver los recursos de su ámbito (artículo 41.4 TRLCSP).

En tanto no se constituyan los Tribunal Autonómicos correspondientes o se establezca por la normativa autonómica disposiciones específicas para las Corporaciones Locales, debe atenderse a lo que estableció la disposición transitoria segunda de la Ley 34/2010, para determinar el órgano que es competente para resolver este recurso, incorporada como disposición transitoria séptima del TRLCSP: "La competencia para la resolución de los recursos continuará encomendada a los mismos órganos que la tuvieran atribuida con anterioridad".

Esto supone una remisión directa al artículo 37.4 de la LCSP en la redacción original, que debe entenderse que no está íntegramente derogado hasta que todas las CCAA creen sus propios tribunales en cumplimiento del mandato del artículo 41.3 y 4 del TRLCSP. Este precepto establece que:

"serán competentes para resolver el recurso especial el órgano de contratación, cuando se trate de
contratos de una Administración Pública, o el titular del departamento, órgano, ente u organismo al

la Junta de Andalucía, el mismo día de la publicación de esta Orden en el Boletín Oficial de la Junta de Andalucía, lo que se produjo el día 21 de diciembre de 2011.

20 Bernal Blay, M.A., "Aspectos orgánicos del recurso especial en materia de contratación pública en las comunidades autónomas", en “Cuadernos de Derecho Local” (QDL), Fundación Democracia y Gobierno Local, junio de 2011, págs. 7 a 26.

21 Ley 19/2010, de 22 de diciembre, de medidas financieras y de creación del Ente Público Agencia de Innovación y Financiación Empresarial de Castilla y León, recoge en su Disposición final séptima, dedicada al Recurso especial en materia de contratación, que: “En cumplimiento de lo dispuesto en los apartados 2 y 3 del artículo 311 de la Ley 30/2007, de 30 de octubre, de Contratos del Sector Público, en el ámbito de la Comunidad de Castilla y León y de las Entidades locales de Castilla y León, la Junta de Castilla y León creará un órgano con competencia para la resolución de las impugnaciones reguladas en la citada norma".

La Ley 1/2012, de 28 de febrero, de Medidas Tributarias, Administrativas y Financieras de Castilla y León crea el Tribunal Administrativo de Recursos Contractuales de Castilla y León como órgano colegiado (arts. 58 a 64), adscrito al Consejo Consultivo de Castilla y León. El Presidente del Tribunal lo será el Presidente del Consejo Consultivo de Castilla y León. Serán Vocales del Tribunal dos Consejeros Electivos del Consejo Consultivo de Castilla y León. El Tribunal Administrativo de Recursos Contractuales de Castilla y León ejercerá sus competencias en el ámbito de los órganos, entes, organismos y entidades que tienen la consideración de poder adjudicador que se integran en la Administración de la Comunidad Autónoma de Castilla y León y en las Entidades Locales de su ámbito territorial. Las Cortes de Castilla y León, el Procurador del Común y el Consejo de Cuentas podrán acudir al Tribunal Administrativo de Recursos Contractuales de Castilla y León, previa celebración del correspondiente convenio con el propio Tribunal, para encomendarle la tramitación y resolución de los recursos, solicitudes de adopción de medidas provisionales y cuestiones de nulidad.

22 Vázquez Matilla, F.J., plantea la necesidad de actualizar la normativa navarra en el artículo "Comentario a la sentencia del Tribunal de Justicia de las Comunidades Europeas de 3 de abril de 2008. La vulneración de la Directiva sobre recursos y su incidencia en la normativa sobre contratación administrativa en Navarra", Revista Jurídica de Navarra, enero-junio 2008, № 45, págs. 149 a 181. El 15 de octubre de 2012 el Parlamento de Navarra publicó dos proyectos de Ley foral que pretenden modificar la normativa sobre contratación pública para adaptar dicha normativa a la Directiva 2007/66/CE, y a los pronunciamientos del Tribunal de Justicia Europeo sobre recursos y modificaciones de contratos. Sobre el recurso en la CCAA de Baleares, véase la aclaración de la nota al pie n 6 .

23 La Ciudad Autónoma de Melilla suscribió un convenio el 9 de julio de 2012; la CCAA de la Rioja el 30 de julio de 2012; Extremadura el 9 de agosto; Castilla La Mancha el 15 de octubre. En estos convenios se prevé el pago de las CCAAA por los servicios del Tribunal, con una cantidad fija y otra variable a partir de determinado número de recursos, cantidades que varían en función del volumen de trabajo previsible en cada casa, desde los $1.500 €$ fijos en el caso de Melilla a 20.000 ene I caso de Castilla La Mancha.

24 El artículo 311.3 del anteproyecto de Ley disponía lo siguiente:

“3. En el ámbito de las Corporaciones locales la competencia corresponderá a un órgano independiente creado al efecto por las Diputaciones Provinciales o por la Comunidad Autónoma cuando ésta esté integrada por una sola provincia.

En la Comunidad Autónoma de Canarias la competencia corresponderá a un órgano creado en cada una de las provincias que la integran por el Gobierno de Canarias, en los términos que determine su legislación. La designación del titular se efectuará por el Consejo de Ministros a propuesta del Presidente de la Diputación a través del Ministro de Economía y Hacienda entre funcionarios juristas de reconocida competencia y con más de 10 años de ejercicio profesional. En todo lo demás será de aplicación lo establecido en el apartado 1 de este mismo artículo. Podrán las Corporaciones Locales, asimismo, atribuir la competencia para la resolución de los recursos al Tribunal especial creado en el apartado 1 de este artículo." 
que esté adscrita la entidad contratante o al que corresponda su tutela, si ésta no tiene el carácter de Administración Pública".

Por lo tanto, mientras las CCAA no creen estos tribunales u órganos especiales, en las Entidades locales, estos recursos se resolverán por el órgano de contratación, y en los contratos de organismos dependientes de las EELL que no sean Administración pública, corresponderá resolver el recurso al órgano al que esté adscrita la entidad contratante o al que corresponda su tutela, generalmente el Pleno de la Corporación (art. 37.4 LCSP).

Esta cuestión ha sido ya analizada por el Tribunal Administrativo Central de Recursos Contractuales, en su resolución 036/2011, de 24 de febrero de 2011, donde inadmite un recurso contra una adjudicación por entender que el órgano competente para resolverlo no es ese Tribunal, sino el Pleno del Ayuntamiento afectado ${ }^{25}$. Considera el Tribunal Central lo que hace la Ley es prever un "mero recurso previo al contencioso" y que es el recurso que se puede interponer ante la Jurisdicción Contencioso Administrativa el que tiene en estos casos la consideración del recurso especial regulado en la Directiva 2007/66/CE ${ }^{26}$. El Tribunal se manifiesta en los términos siguientes:

“(... ) no puede admitirse la afirmación de que la Disposición Transitoria Segunda de la Ley 34/2010, de 5 de agosto, es contraria a la Directiva 2007/66/CE. En efecto, la citada Directiva en su artículo 1.5 dispone que "los Estados miembros podrán exigir que la persona interesada interponga recurso en primer lugar ante el poder adjudicador. En tal caso, los Estados miembros velarán por que la interposición de dicho recurso conlleve la suspensión inmediata de la posibilidad de celebrar el contrato". Esto es precisamente lo que ha hecho la citada Disposición Transitoria Segunda para el caso de que las Comunidades Autónomas no tuvieran establecido el órgano independiente que deben crear de conformidad con lo dispuesto en el artículo 311, apartados 2 y 3, prever que en tales supuestos, los particulares interpongan previamente recurso ante el órgano de contratación y que su interposición comporte la suspensión automática de la adjudicación cuando sea este acto el recurrido. Así se deduce con toda claridad de la citada Disposición (la reproduce el fallo...). Lo que hace no es sino rebajar, por así decir, la condición del recurso administrativo que pasa a ser un mero recurso previo al contencioso", si bien, en aplicación del artículo 1.5 de la Directiva que antes se ha transcrito si se interpusiera contra la adjudicación deberá llevar aparejada la suspensión del acto administrativo, tal como el mencionado precepto exige.

El recurso especial regulado como núcleo fundamental de la Directiva 2007/66/ CE, no es, en este régimen, el que se interpone ante el órgano administrativo, que por supuesto no tiene la condición de independiente, sino el que se puede interponer ante la Jurisdicción Contencioso administrativa. Ello se deduce del inciso de la letra d) de la Disposición Transitoria que se examina a tenor de la cual "las resoluciones dictadas en estos procedimientos serán susceptibles de recurso contencioso-administrativo. Cuando las resoluciones no sean totalmente estimatorias o cuando siéndolo hubiesen comparecido en el procedimiento otros interesados distintos del recurrente, no serán ejecutivas hasta que sean formes o, si hubiesen sido recurridas, hasta tanto el órgano jurisdiccional competente no decida acerca de la suspensión de las mismas". Por lo que añade que "en este caso la interposición del recurso contencioso administrativo sí suspende, o por mejor decir, mantiene la suspensión, del acto administrativo impugnado a diferencia de lo que ocurriría si el órgano independiente ya se hubiera constituido.

Así pues, en base a los argumentos expuestos debe sentarse la conclusión que la Disposición Transitoria Segunda es plenamente acorde con la Directiva 2007/66/CE al atribuir el conocimiento de los recursos especiales en materia de contratación a los órganos de la Jurisdicción Contencioso Administrativa y establecer la suspensión automática de los actos impugnados".

Esta interpretación parece conjugable con las posibilidades que ofrece la Directiva 2007/66/CE, pues en su artículo 2.9 hace expresa referencia a "cuando los órganos responsables de los procedimientos de recurso no sean de carácter jurisdiccional (...)”, por lo que, a sensu contrario, pueden tener ese carácter.

El régimen competencial que establece el artículo 41 del TRLCSP prevé otra especialidad en su apartado 6 para los contratos subvencionados por poderes adjudicadores sujetos a regulación armonizada. La competencia corresponderá al órgano independiente que ejerza sus funciones respecto de la Administración a que esté adscrito el ente u organismo que hubiese otorgado la subvención, o al que esté adscrito la entidad que la hubiese conce-

25 Se trataba de un recurso contra la adjudicación de un contrato por parte de la Sociedad del Palacio de Exposiciones y Congresos de León, S.A., de la que es titular el Ayuntamiento de esa ciudad.

26 Esta interpretación parece asumida por la Recomendación de la Junta Consultiva de Contratación Administrativa de 1 de marzo de 2012, sobre la interpretación del régimen contenido dentro de la disposición transitoria séptima, norma d) del Texto Refundido de la Ley de Contratos del Sector Público.(BOE de 10 de abril). 
dido, cuando ésta no tenga el carácter de Administración Pública. Asimismo, prevé que en el caso de concurrencia de subvenciones por parte de distintos sujetos del sector público, la competencia se determinará atendiendo a la subvención de mayor cuantía y, a igualdad de importe, al órgano ante el que el recurrente decida interponer el recurso de entre los que resulten competentes con arreglo a los anteriores apartados del artículo 41 TRLCSP. A este tipo de contratos también se refiere el Tribunal Administrativo Central de Recursos Contractuales, en su resolución 036/2011, de 24 de febrero de 2011, recordando que este precepto se refiere a contratos celebrados por entidades que no tienen la consideración de poder adjudicador, pues a éstos se les aplica, con mayor o menor intensidad, el TRLCSP. Cuando existe en contrato celebrado por un poder adjudicador y subvencionado por otro u otros poderes adjudicadores, no debe considerarse como contrato subvencionado a los efectos del artículo 17 del TRLCSP, sino como un contrato cofinanciado por diversas Administraciones o podres adjudicadores, aunque "se haya utilizado la fórmula de la subvención a la hora de articular el título jurídico de entrega de los fondos con el objeto de garantizar en mejor forma la inversión".

En conclusión, en el ámbito local, en tanto las respectivas Comunidades Autónomas no creen sus propios órganos para resolver el recurso especial en materia de contratación, la competencia para resolver este recurso corresponde al órgano de contratación.

En todo caso, ha de entenderse que este recurso es un mero recurso previo al contencioso, y este último es el que hace, las veces del recurso exigido en la Directiva 2007/66/CE hasta que se desarrolle la normativa autonómica al respecto.

\section{EFECTOS Y PROCEDIMIENTO A SEGUIR ANTE LA INTERPOSICIÓN DEL RECURSO ESPECIAL EN MATERIA DE CONTRATACIÓN}

\subsection{Efectos suspensivos o no suspensivos de la interposición del recurso especial en materia de contratación}

El artículo 45 del TRLCSP, al igual que el artículo 1.5 de la Directiva 2007/66/CE, dispone expresamente que “(...) si el acto recurrido es la adjudicación, quedará en suspenso la tramitación del expediente de contratación”, y el artículo 46.3 del TRLCSP, en su párrafo segundo señala que la suspensión en este caso es "automática", debiendo el órgano que resuelva el recurso pronunciarse sobre la procedencia del mantenimiento o no de dicha suspensión en el plazo de 5 días concedido a los interesados para formular alegaciones.

Por lo tanto, a sensu contrario, la interposición del recurso especial en materia de contratación contra los actos de trámite, como podría ser la propuesta de adjudicación que implique la exclusión de un licitador, no supondrá la suspensión automática del procedimiento de contratación, de manera que el procedimiento para adjudicar el contrato puede continuar, si bien, el recurrente podría solicitar dicha suspensión como medida cautelar al amparo de la facultad que les confiere el artículo 43 del TRLCSP de solicitar la adopción de medidas provisionales (previa constitución de garantía si de las medidas solicitadas se pudieran derivar perjuicios de cualquier naturaleza). Este carácter potestativo de la suspensión del procedimiento cuando el acto recurrido no es la adjudicación, se deduce también de lo establecido en el artículo 43.4 del TRLCSP, al referirse a la "suspensión del procedimiento que «pueda» adoptarse cautelarmente", es decir, puede a adoptarse o no, en función de que sea o no solicitado, y de las consecuencias de la suspensión, tanto para la contratación pretendida como para la garantía de los derechos de los recurrentes de poder disponer de una revisión efectiva y a tiempo de su reclamación.

La solicitud de suspensión del procedimiento en los casos en los que la suspensión no sea automática, puede realizarla el recurrente antes (art. 43.1), en el mismo momento (art. 44.2), o después de interponer el recurso, en algún momento antes de la resolución del recurso (art. 46.3.2 TRLCSP). Sobre la solicitud de suspensión del procedimiento u otra medida cautelar que se solicite por el interesado, se debe dar audiencia al órgano de contratación para que formule las oportunas alegaciones sobre tal petición, alegaciones que no caben en el caso de recurso contra la adjudicación, ya que en este caso la suspensión es automática por imperativo del artículo 45 del TRLCSP.

En el caso de que las Comunidades Autónomas no tuvieran establecido el órgano independiente que deben crear o no hayan suscrito convenio con el Tribunal Administrativo Central de Recursos Contractuales, los recursos contra los actos de adjudicación que se plantean ante los tribunales de la jurisdicción contencioso administrativa tienen carácter suspensivo de la celebración del contrato hasta que dicha jurisdicción se haya pronunciado sobre el fondo o sobre las medidas provisionales ${ }^{27}$.

27 Así se establece en la Recomendación de la Junta Consultiva de Contratación Administrativa de 1 de marzo de 2012 , sobre la interpretación del régimen contenido dentro de la disposición transitoria séptima, norma d) del Texto Refundido de la Ley de Contratos del Sector Público. 


\subsection{Procedimiento para la resolución de recurso especial}

La tramitación del recurso especial en materia de contratación se rige por lo establecido en la Ley 30/1992, de 26 de noviembre, de Régimen jurídico de las Administraciones Públicas y del Procedimiento Administrativo Común (arts. 107 a 120), con las especialidades que se establecen en los artículos 44 a 47 del TRLCSP. De manera esquemática ${ }^{28}$, el iter procedimental para la resolución de este recurso es el siguiente:

1. Anuncio previo de inicio del procedimiento (art. 44.1 TRLCSP). A la interposición del recurso ha de preceder una comunicación previa y por escrito al órgano de contratación, de que se va a presentar dicho recurso. Se puede plantear si la comunicación de la interposición del recurso es un trámite previo que conlleva, al igual que en el ámbito del recurso contencioso administrativo (art. 45.1 de la Ley 29/1998, de 13 de julio) un pronunciamiento expreso del órgano de contratación poniendo al interesado de manifiesto el expediente para su análisis, comenzando ya el plazo de quince (15) días hábiles para presentar el recurso desde la notificación del acto impugnado. Sin embargo, la exigencia de pronunciamiento expreso por el órgano de contratación no se recoge expresamente en la Ley, por lo que quizá deba descartarse esta interpretación en aplicación del principio general de hermenéutica normativa de "donde la ley no distingue no se debe distinguir", y por lo tanto entender que ese trámite no existe en el recurso administrativo especial. De hecho parece clara la literalidad del artículo 44 del TRLCSP al respecto, y en el plazo de 15 días de que disponen los interesados para la interposición del recurso (art.44.2 TRLCSP) han de remitir al órgano de contratación un anuncio por escrito en el que especifiquen el acto del procedimiento que van a recurrir y en el mismo plazo el escrito de interposición, con todo el contenido que se establece en el apartado 4 de este artículo 314. Por ello no parece muy clara la utilidad de este anuncio de la interposición del recurso, cuya deficiencia además se puede subsanar, conforme se establece en el artículo 44.4.e del TRLCSP, de manera que, como se ha expuesto, su objetivo parece ser simplemente el advertir al órgano de contratación de la conveniencia de no continuar la tramitación del expediente en tanto llegue y se analice el recurso.

2. Plazo para interponer el recurso especial (44.2 TRLCSP): Quince (15) días hábiles. El recurso ha de ser interpuesto en el plazo de quince días hábiles ante el órgano de contratación o ante el órgano que se estime competente para su resolución ${ }^{29}$. Este plazo se computa a partir del día siguiente al que se remita la notificación del acto impugnado. Si lo que se recurre es un acto que no es objeto de notificación particular, este precepto establece como dies a quo los siguientes:

- Si se recurren los pliegos u otros documentos contractuales, el plazo comienza a contar desde aquel en que los mismos han sido puestos a disposición (insertado en el perfil del contratante generalmente) o recibidos por el recurrente (por ejemplo en un procedimiento restringido o en un diálogo competitivo).

- Cuando el recurso se interponga contra actos de trámite adoptados en el procedimiento de adjudicación o contra un acto resultante de la aplicación del procedimiento negociado sin publicidad, el cómputo se iniciará a partir del día siguiente a aquel en que se haya tenido conocimiento de la posible infracción.

- Si lo que se recurre es el anuncio de licitación, el plazo comenzará a contarse a partir del día siguiente al de publicación.

En el recurso se señalará el acto recurrido, el motivo que fundamente el recurso, los medios de prueba de que pretenda valerse el recurrente y, en su caso, las medidas provisionales, cuya adopción solicite. Se ha de acompañar al recurso: a) documento que acredite la representación del compareciente, salvo si figurase unido a las actuaciones de otro recurso pendiente ante el mismo órgano, en cuyo caso podrá solicitarse que se expida certificación para su unión al procedimiento; b) documento o documentos que acrediten la legitimación del actor cuando la ostente por habérsela transmitido otro por herencia o por cualquier otro título; c) copia o traslado del acto expreso que se recurre o indicación del expediente en que ha recaído el acto que se impugna o del boletín/ periódico oficial o perfil de contratante que lo publica; d) documento o documentos en que funde su derecho y e) justificante de haber realizado el anuncio previo de interposición del recurso a que se refiere el apartado 1 del artículo 44 del TRLCSP. Los defectos en el documento de interposición o en los que se acompañan a éste (entre los que se incluye la falta de comunicación previa de la interposición del recurso, art. 314.e) se podrán corregir en un plazo de tres días hábiles y si así no lo hiciera, se le tendrá por desistido de su petición, quedando suspendida la tramitación del expediente con los efectos previstos en el apartado 5 del artículo 42 de la Ley 30/1992, de 26 de noviembre.

28 Puede verse un análisis del procedimiento de interposición y resolución del recurso especial en el trabajo citado de Díez Sastre, S., "El recurso especial en materia de contratación pública", Anuario de Derecho Municipal de 2011, n 5, Marcial Pons e Instituto de Derecho Local, págs. 129 a 165.

29 La Resolución de 3 de noviembre de 2011 del Tribunal Administrativo de Contratación Pública de la Comunidad de Madrid inadmite por extemporáneo el recurso que analiza. 
3. Notificación del recurso al órgano de contratación (art. 46.2 TRLCSP): Un (1) día. El mismo día que se interpone el recurso, el órgano competente para resolverlo lo notificará al órgano de contratación con remisión de la copia del escrito de interposición, y reclamará el expediente de contratación correspondiente a la entidad, órgano o servicio que lo hubiese tramitado. La función de este notificación es dar conocimiento al órgano de contratación de la interposición del citado recurso ya que, además, si lo recurrido fuera la adjudicación, inmediatamente habría que suspender el procedimiento, de ahí la trascendencia de esta comunicación.

A la fecha de redactarse este trabajo, el Tribunal Administrativo Central de Recursos contractuales, dado el volumen de recursos que está recibiendo, no está cumpliendo este plazo ${ }^{30} \mathrm{ni}$, por lo tanto, el resto de los que establecen los artículos 46 y 47 del TRLCSP.

4. Remisión del expediente por el órgano de contratación al competente para resolver el recurso (art. 46.2.2 TRLCSP): Dos (2) días hábiles. El órgano de contratación deberá remitir el expediente dentro de los dos días hábiles siguientes a la notificación de la interposición del recurso por parte del órgano competente para resolver el citado recurso.

Junto con el expediente, el órgano de contratación habrá de acompañar el "correspondiente informe". Sin embargo, el artículo 46.2 del TRLCSP no aclara qué tipo de informe ha de ser el que se ha de incorporar al expediente:

a) si un informe en el que se analice el recurso de manera completa, esto es, considerando la impugnabilidad del acto recurrido, la legitimación activa de los recurrentes, las medidas cautelares solicitadas, así como el fondo del recurso y expresando el parecer de las asesorías (jurídica, y, en su caso, técnica) sobre el mismo,

b) o si ha de ser un mero informe de trámite, en el que se expongan las actuaciones realizadas hasta la fecha del recurso y se analice la competencia para su resolución y, en su caso, las consecuencias para el procedimiento de la adopción de las medidas cautelares solicitadas.

Si el recurso se interpone directamente ante el órgano de contratación, éste deberá remitir directamente el expediente al órgano encargado de su resolución en el mismo plazo de 2 días hábiles, junto con el referido informe.

En cuanto el contenido mínimo que el Tribunal Administrativo Central de Recursos Contractuales considera que compone el expediente de contratación que debe remitírsele, es el siguiente ${ }^{31}: 1$. Índice de la documentación que se adjunta; 2 . Informe del órgano de contratación al recurso; 3. Relación de licitadores con su dirección (incluida la de correo electrónico), a efectos de notificaciones; 4 . Documentación acreditativa del poder del representante de la empresa recurrente; 5. Pliegos de Cláusulas Administrativas Particulares y Pliegos de Prescripciones Técnicas (completos incluidos Anexos / Cuadro de características); 6. Anuncios de licitación; 7. Certificado de entrada de las proposiciones (documentación administrativa, oferta técnica y oferta económica) de todos los licitadores; 8. Documentación íntegra (documentación administrativa, oferta técnica y oferta económica) del licitador recurrente y, en su cado, del adjudicatario, en el supuesto que el contenido de las mismas sea el objeto del recurso o resulte necesaria para su resolución: 9. Notificaciones de los diferentes actos realizadas a los licitadores recurrente y adjudicatario, debiendo incluirse tanto el escrito enviado como el justificante de la notificación del mismo, cuando sean necesarias para la resolución del recurso. -Acuerdo de exclusión. -Acuerdo de adjudicación. -Otras notificaciones en virtud de las cuales se haya solicitado la subsanación de defectos observados en la documentación, posibles retrasos en los actos públicos de apertura de las ofertas, desistimiento del procedimiento por la Administración, etc.; 10. Actas de la Junta/Mesa de Contratación referidas al examen de la documentación administrativa, así como a la apertura de las ofertas técnicas y económica, y demás en las que se haga referencia al expediente objeto de recurso; 11. Informes realizados para la valoración de las ofertas, si resultan necesarios de acuerdo con el recurso interpuesto; 12. Toda aquella documentación que, de acuerdo con el recurso interpuesto, entienda el órgano de contratación que, pueda ser necesaria para la resolución del recurso.

5. Alegaciones de los interesados: Diez (10) días que se corresponden con cinco (5) días para trasladar a los restantes interesados la interposición del recurso y otros cinco (5) días para que estos últimos formulen alegaciones. Así pues, el artículo 46.3 del TRLCSP establece un plazo de 5 días hábiles para comunicar a los demás interesados la interposición de recurso y ponerles de manifiesto el expediente, concediéndoles un plazo de otros 5 días hábiles para formular alegaciones.

De forma simultánea al trámite de alegaciones de los restantes interesados y en el plazo de cinco (5) días hábiles, el órgano encargado de resolver el recurso ha de decidir sobre la adopción o no de las medidas cautelares

30 Así se ha puesto de manifiesto con ocasión de un recurso especial interpuesto contra un contrato de obras tramitado por una sociedad municipal del Ayuntamiento de León, al que corresponde la resolución 036/2011 del Tribunal Administrativo Central de Recursos Contractuales.

31 De acuerdo con lo requerido por el TACRC en el recurso al que corresponde la resolución 036/2011. 
que, en su caso, se hubiesen solicitado en el escrito de interposición del recurso o se hubiera procedido a la acumulación prevista en el párrafo tercero del artículo 43.2 del TRLCSP, incluso sobre la suspensión automática si el recurso se interpone contra la adjudicación del contrato, suspensión ésta que se mantendrá vigente en tanto no se acuerde expresamente su levantamiento. Estas medidas se adoptarán previa audiencia del órgano de contratación, y podrán llevar aparejada la exigencia de "caución o garantía suficiente" para responder de los perjuicios de cualquier naturaleza que puedan derivarse de la adopción de las medidas provisionales, conforme prevé el artículo 43.3 del TRLCSP.

Tanto en este traslado del expediente como en el periodo de prueba, ha de garantizarse la confidencialidad y el derecho a la protección de los secretos comerciales en relación con la información contenida en el expediente de contratación (oferta, cualidades de solvencia de los licitadores, etc.) y el derecho de los demás interesados a una protección jurídica efectiva y a su derecho de defensa en el procedimiento. El órgano competente para resolver el recurso se ha de pronunciar expresamente sobre cómo conjugar ambos derechos, sin que el TRLCSP de ninguna pista al respecto (art. 46.5). Una forma de combinar ambos derechos cuando, transitoriamente, el órgano para resolver sea el órgano de contratación, puede ser concediendo acceso al expediente en la dependencia administrativa donde se tramite el contrato, pudiendo analizar toda la documentación administrativa y respecto de la aportada por los licitadores, solamente aquella que sea objeto de recurso (así, por ejemplo, si se discute la valoración otorgada a la oferta contenida en el sobre que contiene la oferta valorable matemáticamente, se deberá permitir el acceso a ésta pero no al sobre que contenga la oferta no valorable matemáticamente, puesto que ésta no es objeto de recurso) y no se debería permitir hacer copias de ningún documento aportado por los licitadores.

6. Periodo de prueba (art. 46.4 TRLCSP): Diez (10) días hábiles. Los interesados podrán solicitar la apertura del período de prueba. Además, el órgano encargado de la resolución del recurso cuando no tenga por ciertos los hechos alegados por los interesados o la naturaleza del procedimiento lo exija, podrá realizar las pruebas que estime necesarias para acreditar las alegaciones o valorar las actuaciones realizadas. Puede efectuarse cualquier medio de prueba admisible en derecho, y podrán rechazarse, motivadamente, las que el Tribunal u órgano que haya de resolver estime improcedentes o innecesarias. El periodo de prueba será como máximo de 10 días hábiles y su práctica se anunciará con la antelación suficiente a los interesados (supletoriamente artículos 80 y 81 LRJyPAC).

7. Resolución y Notificación (art. 47 TRLCSP): Cinco (5) días hábiles para dictar resolución y, a continuación, procederá la notificación a todos los interesados. Recibidas las alegaciones de los interesados, o concluido el plazo para formular alegaciones y, en su caso, el periodo de prueba, el órgano competente para la resolución del recurso deberá dictar, dentro de los cinco días hábiles siguientes, resolución motivada estimando en todo o en parte el recurso, o desestimándolo o declarará su inadmisión. Deberá decidir cuantas cuestiones se hubiesen planteado de manera congruente con la petición formulada por los recurrentes, pronunciándose, en su caso, sobre la anulación de las decisiones ilegales adoptadas durante el procedimiento de adjudicación y sobre las indemnizaciones procedentes por daños y perjuicios, así como, si procede, la retroacción de actuaciones. Asimismo, la resolución deberá acordar, también, el levantamiento de la suspensión del acto de adjudicación si en el momento de dictarla continuase suspendido, así como de las restantes medidas cautelares que se hubieran acordado y la devolución de las garantías cuya constitución se hubiese exigido, si procediera.

La resolución se comunicará a todos los interesados. El TRLCSP no especifica el plazo de notificación, pero habrá que entender que se ha de realizar dentro del plazo de 10 días que establece el artículo 195 del Reglamento de Organización, Funcionamiento y Régimen Jurídico de las Entidades Locales. Este precepto dispone que: que "Las providencias de trámite y los actos o acuerdos que pongan término a un expediente serán notificados en los diez días siguientes al de su fecha". Entendemos que el acto por el que se resuelve un recurso es un "acuerdo que pone término a un expediente", por lo que éste sería el plazo para notificar el acuerdo de resolución del recurso, en lugar del plazo genérico de 3 meses previsto en el artículo 42.3 de la Ley 30/1992 para los procedimientos en los que no se especifica el plazo máximo de resolución y notificación, contando el mismo desde la fecha que entró el recurso en el registro del órgano competente para su tramitación. Este plazo de 10 días se conjuga mejor con la exigencia de agilidad en la tramitación y resolución del recurso (Directiva 66/2007/CE, exposición de motivos, apartado 2, y artículo 2).

Contra la resolución sólo cabe la interposición del recurso contencioso administrativo (art. 49 TRLCSP). Así pues, tampoco procederá la revisión de oficio regulada en el artículo 34 del TRLCSP y en el Capítulo I del Título VII de la Ley 30/1992 y tampoco estarán sujetos a fiscalización por los órganos de control financiero de las Administraciones a que cada uno de ellos se encuentre adscrito (art. 49.1 in fine).

Si como consecuencia de la resolución del recurso procede la adjudicación del contrato a otro licitador, se le concederá el plazo de diez días hábiles para aportar los documentos justificativos de hallarse al corriente de 
sus obligaciones tributarias y con la Seguridad Social, de disponer efectivamente de los medios que se hubiese comprometido a dedicar o adscribir a la ejecución del contrato conforme al artículo 64.2 del TRLCSP y constituir la garantía definitiva (art. 47.2 TRLCSP).

8. Resolución del recurso por silencio administrativo: Con la anterior redacción de la LCSP, el art. 37.9 señalaba que "en todo caso, transcurridos veinte días hábiles contados desde el siguiente a la interposición del recurso sin que se haya notificado su resolución, el interesado podrá considerarlo desestimado a los efectos de interponer recurso contencioso-administrativo". La regulación introducida por la Ley 34/2010 e incorporada al TRLCSP, no recoge una previsión expresa al respecto, por lo que habrá de considerar el plazo máximo resultante de la suma de los plazos que se otorgan para cada uno de los trámites en los artículos 46 y 47 del TRLCSP: 28 días hábiles, y 10 días más para notificar el acuerdo de resolución del recurso. Ello, a la vista del antecedente del articulo 37.9 LCSP y de la exigencia de celeridad que la Directiva exige a este recurso ${ }^{32}$.

En cuanto a los efectos del silencio, nada dice la Ley de Contratos, lo que implica que no hay ninguna especialidad con respecto al régimen general de la Ley de Procedimiento Administrativo. De acuerdo con lo establecido en el artículo 43 LRJyPAC, "los procedimientos de impugnación de actos y disposiciones, en los que el silencio tendrá efecto desestimatorio"; es decir, si no se resuelve el plazo máximo de 28 días hábiles desde que se interpuso el recurso especial, se ha de entender desestimado por silencio el mismo. Esto supone abrir la vía del recurso contencioso para los recurrentes a partir de esa fecha, sin perjuicio de que el órgano competente para resolver lo ha de hacer en todo caso, aún fuera de plazo, y sin estar vinculado por el sentido negativo del silencio (art. 43.4.b LRJyPAC).

\subsection{Análisis especial de la ejecutividad de la resolución del recurso especial}

De acuerdo con el art. 49 TRLCSP, la resolución del recurso será directamente ejecutiva, resultando de aplicación lo dispuesto en el artículo 94 de la Ley 30/1992, de 26 de noviembre (en el mismo sentido el 97 relativo al apremio sobre el patrimonio).

Sin embargo, las disposición transitoria séptima del TRLCSP, que como se ha reiterado incorpora literalmente la disposición transitoria segunda de la Ley 34/2010, matiza la anterior regla en el ámbito de las Comunidades Autónomas y Entidades Locales en tanto aquellas no dicten normas de desarrollo en relación con el recurso especial, y señala, en su letra d, que:

"Ias resoluciones dictadas en estos procedimientos serán susceptibles de recurso contencioso-administrativo. Cuando las resoluciones no sean totalmente estimatorias o cuando siéndolo hubiesen comparecido en el procedimiento otros interesados distintos del recurrente, no serán ejecutivas hasta que sean firmes o, si hubiesen sido recurridas, hasta tanto el órgano jurisdiccional competente no decida acerca de la suspensión de las mismas".

Así pues, la resolución del recurso en los casos a que se refiere esta disposición transitoria, devengará en firme una vez transcurrido el plazo de dos meses para interponer el recurso contencioso-administrativo y será entonces cuando devengará en ejecutivo, rompiéndose así la regla general prevista en el artículo 94 de la Ley 30/1992, de que "los actos de las Administraciones Públicas sujetos al Derecho Administrativo serán inmediatamente ejecutivos"33.

Éste régimen tan severo para las Comunidades Autónomas y Entidades Locales puede que obedezca a que el legislador estatal ha pretendido impulsar a las Comunidades Autónomas para que no demoren la creación de los correspondientes tribunales regionales y su desarrollo normativo. En esa normativa autonómica éstas podrán establecer un precepto análogo al actual artículo 49 TRLCSP, es decir, fijar que la resolución del recurso será directamente ejecutiva y no, como sucede con la redacción heredada en el TRLCSP de la disposición transitoria segunda de la Ley 34/2010, que no son ejecutivas hasta que no sean firmes.

Esta intencionada demora en la ejecutividad de la resolución del recurso en estos casos puede ocasionar ciertos trastornos en la ejecución del contrato, ya que al no ser ejecutiva la resolución, habrá que esperar hasta

32 La exposición de motivos de la Directiva 2007/66/CE señala en su apartado 2 que "los Estados miembros deben garantizar que dé medios de recurso eficaces y rápidos contra decisiones adoptadas por poderes adjudicadores y entidades contratantes". El artículo 2.1.a exige, por ejemplo, que el sistema de recursos prevea la posibilidad de adoptar medidas provisionales "lo antes posible".

33 Esta es la también interpretación que se ha dado en la Recomendación de la Junta Consultiva de Contratación Administrativa (de 1 de marzo de 2012), sobre la interpretación del régimen contenido dentro de la disposición transitoria séptima, norma d) del Texto Refundido de la Ley de Contratos del Sector Público. Cabía la duda si el plazo para que alcanzase firmeza el acuerdo del órgano de contratación en relación sobre el recurso era el de dos meses para interponer el contencioso, o se extendía hasta el momento en que el Juzgado comunicase al órgano de contratación dicha interposición. 
que termine el plazo para interponer el recurso contencioso, con el consiguiente riesgo de no poder cumplir con el plazo de ejecución del contrato, alterando así el ritmo de la ejecución presupuestaria o los plazos para justificar una subvención, si la inversión está cofinanciada: el retraso en la ejecución, ante la falta de ejecutividad de la resolución, puede conllevar la pérdida de financiación, es decir, un trastorno que se debe resolver por el legislador autonómico en la mayor brevedad posible. Además, nada asegura que la comunicación del Tribunal contencioso al órgano de contratación de la interposición del recurso sea inmediata, sino que se puede producir una vez ya iniciada la ejecución del contrato considerando que la resolución ya era firme y, de nuevo, habrá que suspender el mismo hasta que el Juez de lo contencioso decida, por lo menos, que medidas cautelares adoptan.

\section{CONCLUSIONES}

La Ley 34/2010 introdujo importantes cambios en el régimen de los recursos administrativos en materia de contratación, en transposición de la Directiva 2007/66/CE, de 11 de diciembre, incorporados literalmente al TRLCSP. El objetivo de esta regulación es reforzar el sistema de recursos para lograr una resolución eficaz y rápida contra las decisiones adoptadas por poderes adjudicadores y entidades contratantes en los contratos sometidos a las Directivas comunitarias.

Sin embargo, la eficacia de la Ley en el ámbito autonómico y local depende del desarrollo de la misma por las Comunidades Autónomas y de la creación por éstas de Tribunales específicos en su ámbito geográfico. Entre tanto, el recurso especial ante un órgano interno del poder adjudicador no deja de ser un mero recurso administrativo equivalente al de reposición, pero con la "penalización" de que sus resoluciones, cuando no sean totalmente estimatorias o cuando siéndolo hubiesen comparecido en el procedimiento otros interesados distintos del recurrente, no serán ejecutivas hasta que sean firmes o, si hubiesen sido recurridas, hasta tanto el órganos jurisdiccional competente no decida acerca de la suspensión de las mismas.

El sistema del recurso especial en materia de contratación modificado en la LCSP por la Ley 34/2010, e incorporado al TRLCSP, tiene las características siguientes:

- Es un recurso administrativo, no judicial, específico para determinados contratos, exclusivo y excluyente de otros recursos administrativos cuando resulta procedente (artículo 40.5 TRLCSP), y de carácter potestativo para los legitimados (art. 40.6 TRLCSP).

- Es un recurso con un ámbito de aplicación material y de legitimación limitado. En cuanto a los sujetos legitimados para interponer el recurso especial, se configura en la TRLCSP (artículo 42) una legitimación amplia, estando abierto el recurso a los licitadores, a los perjudicados y a los potencialmente afectados en sus derechos o intereses legítimos por el acto impugnado, sin que sea imprescindible haber participado en la licitación que se pretenda recurrir, pero no existe una acción pública en materia contractual. La legitimación de los corporativos de la Corporación contratante deriva directamente de la general que les atribuye el artículo 63 de la LBRL (Acuerdo 44/2012, de 9 de octubre de 2012, del Tribunal Administrativo de Contratos Públicos de Aragón). Respeto de las UTE, cualquier miembro está legitimado para interponer el recurso especial, siempre y cuando alguna otra de las empresas que integran la UTE no manifieste expresamente estar en contra de la interposición del recurso, en cuyo caso decaería la legitimación activa de los recurrentes.

- En el ámbito objetivo del recurso especial, sólo son objeto de este recurso especial los contratos sometidos a regulación armonizada, que no se sigan por el trámite de emergencia (40.1 y 4 del TRLCSP). Pueden ser objeto del recurso especial los actos dictados en la fase de tramitación de la licitación y adjudicación de un contrato que hayan infringido el Derecho comunitario en materia de contratación públicos o las normas nacionales de incorporación de dicha normativa. El artículo 40.2 del TRLCSP concreta los actos susceptibles de dicho recurso.

- Los actos que se dicten en los procedimientos de adjudicación de contratos administrativos que no estés sometidos a regulación armonizada, podrán ser objeto de recurso ordinario o de reposición de acuerdo con lo establecido en la LRJyPAC. Esta regla es también aplicable a los contratos de naturaleza no administrativa celebrados por las Administraciones Públicas. En cuanto a los contratos celebrados por otras entidades del sector público que no sean Administraciones Públicas ni poderes adjudicadores, podrá establecerse en los pliegos el sometimiento de las cuestiones litigiosas a un sistema de arbitraje de acuerdo con la Ley 60/2003, de 23 de diciembre, de Arbitraje (art. 50 TRLCSP). A estos efectos se ha creado el Tribunal de Arbitraje para la Contratación Pública, es una institución arbitral constituida en el seno de la Asociación Europea de Arbitraje.

—En el ámbito de la Administración del Estado, la resolución de este recurso se ha atribuido en la Ley 34/2010 a un nuevo órgano creado específicamente para este fin, esto es, al Tribunal Administrativo Central de Recursos Contractuales. Para las Comunidades Autónomas, el artículo 41.3 del TRLCSP impone la obligación de crear sus pro- 
pios Tribunales, y en tanto los crean, la competencia para la resolución de los recursos continuará encomendada a los mismos órganos que la tuvieran atribuida con anterioridad (disposición transitoria segunda de la Ley 34/2010 y transitoria séptima del TRLCSP).

- En el ámbito local, en tanto las respectivas Comunidades Autónomas no creen sus propios órganos para resolver el recurso especial en materia de contratación, la competencia para resolver este recurso corresponde al órgano de contratación, (art. 37.4 de la LCSP en su redacción original, por remisión de la disposición transitoria segunda de la Ley 34/2010).

- Este recurso "especial" ante el propio órgano de contratación sería un "mero recurso previo al contencioso", pero es el recurso que se puede interponer ante la Jurisdicción Contencioso Administrativa el que tiene la consideración del "recurso especial” regulado en la Directiva 2007/66/CE (Resolución 036/2011, de 24 de febrero de 2011 del Tribunal Administrativo Central de Recursos Contractuales).

- La tramitación del recurso especial ha de ser ágil, y resolverse en el plazo de 28 días que se deduce del iter procedimental regulado en el artículo 46 del TRLCSP. Sin embargo, la resolución del recurso, en el ámbito de las Entidades Locales (y de las CCAA en tanto no dicten su regulación específica y creen sus respectivos Tribunales) no será ejecutiva hasta que sean firmes o, si hubiesen sido recurridas, hasta tanto el órganos jurisdiccional competente no decida acerca de la suspensión de las mismas, en los casos en los que las resoluciones no sean totalmente estimatorias o cuando siéndolo hubiesen comparecido en el procedimiento otros interesados distintos del recurrente (adicional segunda d) de la Ley 34/2010)".

\section{BIBLIOGRAFÍA}

Ballesteros Arribas, S., "Condena al Reino de España por no haber extendido el sistema de recursos a las empresas públicas y por la necesidad de interponer recurso para que se puedan adoptar medidas cautelares", El Consultor de los Ayuntamientos y los Juzgados, № 17/2003, pp. 2962-2964.

Ballesteros Moffa, L.A., "Comentario a la Ley 34/2010, de 5 de agosto, de modificación de las leyes de contratación pública en materia de recursos, y de la Ley de Jurisdicción Contencioso-Administrativa", Revista Justicia Administrativa, núm. 50, 2011, pp. 25-45.

Ballesteros Moffa, L.A., "La adjudicación de contratos en el sector público", Thomson-Civitas, Navarra, 2010.

Bernal Blay, M.A., "Aspectos orgánicos del recurso especial en materia de contratación pública en las comunidades autónomas", publicado en "Cuadernos de Derecho Local" (QDL), de la Fundación Democracia y Gobierno Local, junio de 2011, pp. 7-26.

Díez Sastre, S., "El recurso especial en materia de contratación pública" Anuario de Derecho Municipal de 2011, $\mathrm{n}^{\circ}$ 5, editado por Marcial Pons y el Instituto de Derecho Local en Madrid, 2012, pp. 129 a 165.

Díez Sastre, S., La tutela de los licitadores en la adjudicación de contratos públicos, Marcial Pons, 2012.

Gallego Córcoles, I., "Legitimación para instar la revisión de decisiones en materia de contratación pública", Contratación Administrativa Práctica, Nㅜㄱ, Sección Informe de Jurisprudencia, Editorial La Ley, Mayo 2008, págs. 47 y ss.

Gallego Córcoles, I., "Contratación del Sector Público Local”, Editorial La Ley-El Consultor, $2^{\mathrm{a}}$ edición 2010, págs. 336 a 347.

Moreno Molina, J.A., "Recursos contra la adjudicación el contrato. Condena a España", Contratación Administrativa Práctica $\mathrm{N}^{\circ} 76,2008$, págs. 20 a 26.

Noguera de la Muela, B., "El recurso especial en materia de contratación y las medidas cautelares en la Ley 30/2007, de 30 de octubre, de Contratos del Sector Público, a la vista de la Directiva 2007/66/CEE, por la que se modifica la directiva 89/665/CEE”, Noticias de la Unión Europa n² 298 (2009), págs. 95 a 111.

Vázquez Matilla, F.J., "Comentario a la sentencia del Tribunal de Justicia de las Comunidades Europeas de 3 de abril de 2008. La vulneración de la Directiva sobre recursos y su incidencia en la normativa sobre contratación administrativa en Navarra", Revista Jurídica de Navarra ISSN: 0213-5795. Enero-Junio 2008, № 45, págs.149 a 181. 